\title{
Review \\ Advances in Medical Wearable Biosensors: Design, Fabrication and Materials Strategies in Healthcare Monitoring
}

\author{
Sangeeth Pillai ${ }^{1} \mathbb{D}$, Akshaya Upadhyay ${ }^{1}$, Darren Sayson ${ }^{1}$, Bich Hong Nguyen ${ }^{2}$ and Simon D. Tran ${ }^{1, *(\mathbb{D})}$ \\ 1 McGill Craniofacial Tissue Engineering and Stem Cells Laboratory, Faculty of Dentistry, McGill University, \\ 3640 University Street, Montreal, QC H3A 0C7, Canada; sangeeth.pillai@mail.mcgill.ca (S.P.); \\ akshaya.upadhyay@mail.mcgill.ca (A.U.); darrensayson@gmail.com (D.S.) \\ 2 Department of Pediatrics, CHU Sainte Justine Hospital, Montreal, QC H3T 1C5, Canada; \\ bich.hong.nguyen@umontreal.ca \\ * Correspondence: simon.tran@mcgill.ca
}

\section{check for}

updates

Citation: Pillai, S.; Upadhyay, A.;

Sayson, D.; Nguyen, B.H.; Tran, S.D. Advances in Medical Wearable Biosensors: Design, Fabrication and Materials Strategies in Healthcare Monitoring. Molecules 2022, 27, 165. https://doi.org/10.3390/ molecules 27010165

Academic Editors: Anna Borriello, Francesca Santoro and

Vincenzo Guarino

Received: 30 November 2021 Accepted: 23 December 2021 Published: 28 December 2021

Publisher's Note: MDPI stays neutral with regard to jurisdictional claims in published maps and institutional affiliations.

Copyright: (C) 2021 by the authors. Licensee MDPI, Basel, Switzerland. This article is an open access article distributed under the terms and conditions of the Creative Commons Attribution (CC BY) license (https:// creativecommons.org/licenses/by/ $4.0 /)$.

\begin{abstract}
In the past decade, wearable biosensors have radically changed our outlook on contemporary medical healthcare monitoring systems. These smart, multiplexed devices allow us to quantify dynamic biological signals in real time through highly sensitive, miniaturized sensing platforms, thereby decentralizing the concept of regular clinical check-ups and diagnosis towards more versatile, remote, and personalized healthcare monitoring. This paradigm shift in healthcare delivery can be attributed to the development of nanomaterials and improvements made to non-invasive biosignal detection systems alongside integrated approaches for multifaceted data acquisition and interpretation. The discovery of new biomarkers and the use of bioaffinity recognition elements like aptamers and peptide arrays combined with the use of newly developed, flexible, and conductive materials that interact with skin surfaces has led to the widespread application of biosensors in the biomedical field. This review focuses on the recent advances made in wearable technology for remote healthcare monitoring. It classifies their development and application in terms of electrochemical, mechanical, and optical modes of transduction and type of material used and discusses the shortcomings accompanying their large-scale fabrication and commercialization. A brief note on the most widely used materials and their improvements in wearable sensor development is outlined along with instructions for the future of medical wearables.
\end{abstract}

Keywords: biosensors; wearable technology; biosensing materials; medical monitoring

\section{Introduction}

Biosensors are devices that utilize biomolecular cues from analytes to process and produce quantifiable signals. The concept of "biosensing" surfaced around the early 20th century with the simple concept of acid concentration in liquids showing proportionality to the electrical potential across a membrane [1]. However, it was not until 1956 that a true biosensor device was developed by Leland C. Clark, Jr. for oxygen detection [2]. Thus began the evolution of an array of biosensor platforms ranging from fiber-optic-based detection of $\mathrm{CO}_{2}$, oxygen [3], and glucose [4], to the use of surface plasmon resonance (SPR) for gas detection [5], with the breakthrough of the first handheld blood biosensor (i-STAT) developed in 1992 [3]. Today, 20 years later, biosensors have made their way into our everyday lives in the form of wearable technology. Ranging from a simple fitness band that counts our daily steps, to highly multiplexed devices that detect non-abundant biochemical markers in body fluids, wearable biosensors have revolutionized our outlook on healthcare monitoring. This means, nowadays, it is possible for us to sit home and get real-time, dynamic information on our physiological functioning, just by a click, a tap, or a scan. These devices can capture different types of biosignals like changes in temperature, pulse, $\mathrm{pH}$, motion, and biochemical composition of body fluids rapidly. In addition, many biosensors are currently developed as rapid, point-of-care devices that can be used 
in large-scale population screening to detect several viruses, including the most recent SARS-CoV-2 [6]. However, a sneak peak of the commercial market of wearable biosensors revealed a battle among the tech giants. A recent post on CBINSIGHTS highlighted that telehealth, wearables, and virtual reality will ace the battle of technologies and industries that shape a post-pandemic world [7]. An economical, easy-to-fabricate, high-throughput multimodal device with superior biocompatibility would naturally see a substantial growth in the industry, if made readily available, and can thereby make an appreciable impact on remote healthcare monitoring. For routine clinical applications, these materials should be comfortable and compatible with human skin surfaces and living tissues to constantly garner biosignals and generate computable results. In addition to ideal biointerfaces, wearable biosensors demand the use of materials that have superior sensitivity for correct recognition of analytes and high selectivity to identify specific types of environmental stimuli at a given time [8]. From the era of stiff electrochemical devices to the development of soft, flexible, and printable functional materials that adhere to jagged skin surfaces, there has been a paradigm shift in the way these modern materials are fabricated and utilized for biosensing applications [9]. In this narrative review, we will first describe an ideal biosensor in terms of the key components and sensing mechanisms while defining biointerfaces. We will then discuss the different types of wearable biosensors based on their sensing platforms, with a focus on the electro-chemical, mechanical, and optical mode of biosensing. We will mainly focus on the advances in biosensing materials and fabrication strategies used for developing these devices, with a brief note on the current challenges and future research focus in this area.

\section{Design, Ideal Requirements, and Types of Wearable Biosensors}

A biosensor is broadly made up of three main components: the biorecognition element, the transducer, and the signal amplifier (Figure 1). The two main areas of focus in this review are the biorecognition element and the transducer.

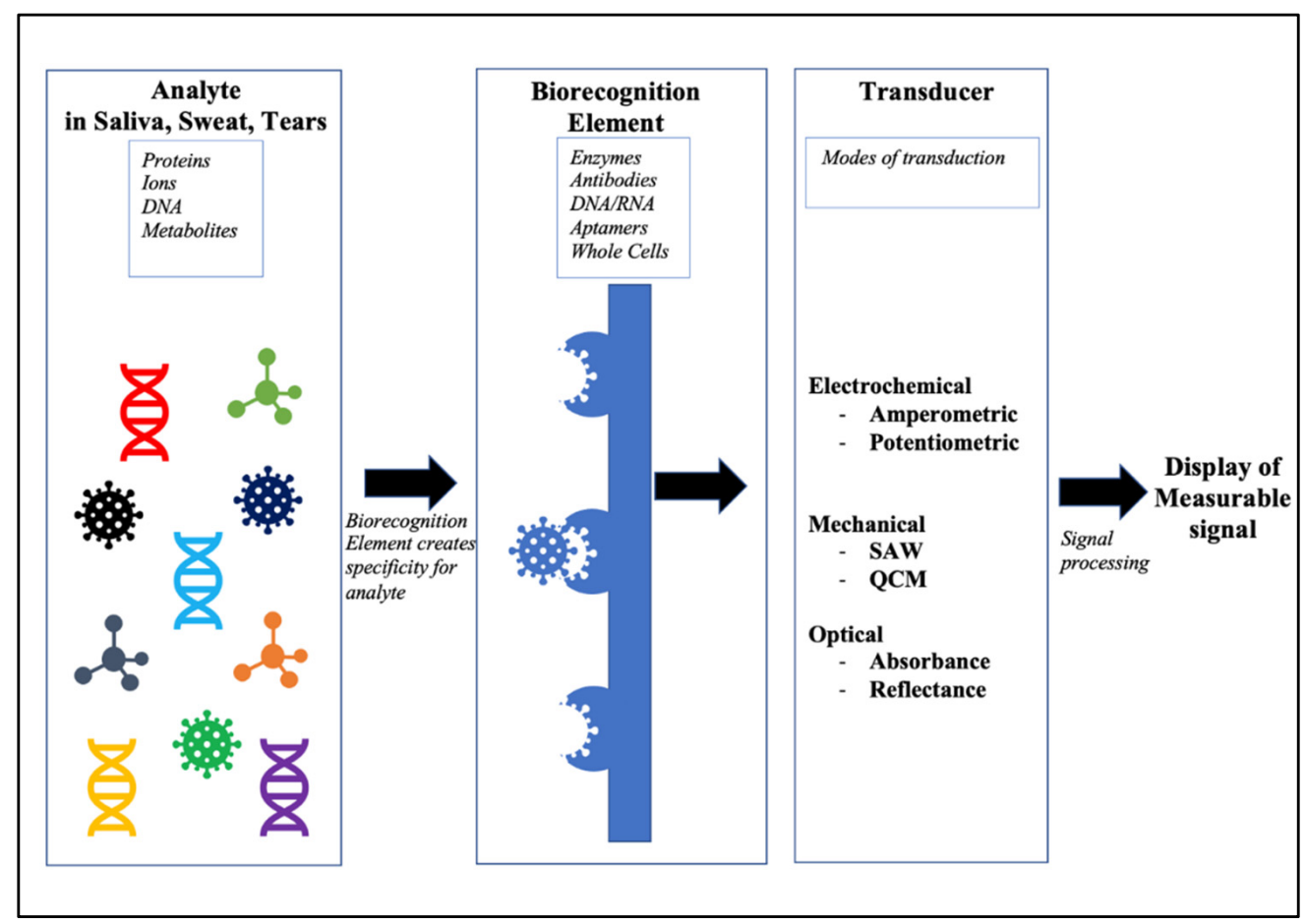

Figure 1. Schematic illustration of the basic parts of a biosensor and the working mechanisms. The analyte is usually the biomolecule that is recognized by the highly specific biorecognition element, and this reaction takes place on different transduction platforms, generating signals that are detected by transducers and converted into displayable data. 
The success of biosensing lies within the recognition element. Typically, antibodies, enzymes, whole cells, and polymers have been used as the biorecognition element, as they allow for high specificity [10]. However, there are challenges when using such sensitive biomolecules-for example, the stability of the proteins for use in wearable devices tend to degrade over time and therefore can provide unreliable data. To overcome this challenge, recent biosensors prefer the use of aptamers, which, in addition to providing that high level of specificity and sensitivity, are also less prone to degradation [11]. These elements are immobilized using several physical and chemical strategies on the sensor to capture the target analyte. Biosensing materials such as hydrogels, graphene, and nanoparticles have gained widespread attention recently for their use as biorecognition elements and transducers [12]. Although biosensors have the same general mechanism for biorecognition, it is in the mode of transduction that they differ. The transducer is responsible for taking the reaction generated by the binding of the analyte to the biorecognition element and converting it to a readout that is proportional to the concentration of the analyte. Using a similar set of parameters as outlined by Luka et al. (2015) [13], this review will evaluate the advances made in wearable biosensors on the three mainly applied modes of transduction: electrochemical, electro-mechanical, and optoelectrical/photo-sensing platforms.

\subsection{Ideal Requirements for Use as Wearable Biosensors}

(a) Comfort: An essential element in the creation of a wearable biosensor is its flexibility and stretchability [14]. The ability to withstand and sense the strain is an important aspect of a device that will be subjected to constant strain and wear. With wearable biosensors that are often worn directly on the skin, there is a significant need for the materials to be adaptive and flexible. Materials that are not biocompatible with skin not only lead to general discomfort for the user, but also to low accuracy, as the biosensor-skin contact is not maintained for long periods due to the mechanical mismatch. Modifications such as the development of skin-inspired and patterned mesh to adapt to the human body's curvilinear surface allows for better-adapted sensors [15]. Materials such as hydrogels, textiles, and paper have been mainstreamed for the development of wearable biosensors, as they provide a flexible, stretchable, and breathable platform for potential applications as wearable biosensors [16-19].

(b) Monitoring several analytes/parameters: An ideal wearable biosensor also has the capacity to monitor several biomarkers while maintaining physical properties. Different biosensor platforms have varying efficiency in measuring the analytes and the type of sample used. Some bioassays still use fluorescence or a colorimetric mode of detection, which poses a challenge to detecting low-abundance analytes.

(c) Biocompatibility: It is essential to fabricate the wearable sensor in such a way that the sensing surface that meets the skin is biocompatible and bioinert, and it must not cause a leakage, release toxic chemical molecules, or degrade due to wear and tear, and must provide adequate comfort while functioning accurately [15].

(d) Other considerations: Although not strictly a material requirement, there are other important considerations for developing a wearable biosensor. Miniaturized design, portability, scalability, and cost remain important factors in the creation of a wearable for widespread use. Although several low-cost and scalable methods have been presented in the literature, for example, devices made by screen-printing as a means of fabricating multiplexed biosensors [20], there is still a knowledge gap between developing a novel biosensor and actually applying it to large population groups.

\subsection{Types of Wearable Biosensors}

Within the literature, wearable biosensors are classified under several categories depending on their design and utility, material of choice, type of bioanalyte/biofluid used, or the transduction platform. Based on their design and utility, they can be divided into biosensors for the head and face or oral cavity, wrist- and arm-based wearables, textile based, and food mounted (Figure 2). Wearable biosensors can also be categorized based on 
the material they are made of, such as carbon based, inorganic biomaterials, or polymers, or categorized as flexible, biocompatible, or biodegradable sensors. Many authors tend to classify biosensors based on the biofluid/bioanalyte used, such as tear-, saliva-, sweat-, or interstitial fluid-detecting sensors, or based on invasiveness, such as subcutaneous and implantable sensors that utilize other physiological biomarkers to monitor health.

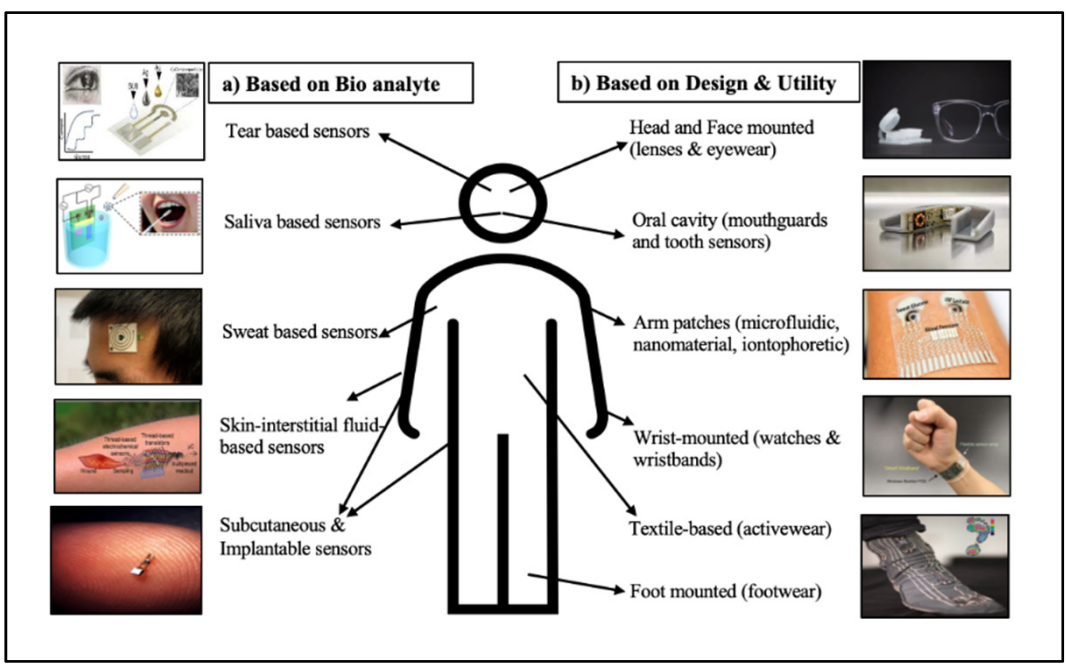

Figure 2. Different types of wearable devices categorized based on (a) bio-analyte and (b) design and utility. Images courtesy of [21-25], Reprinted with permission from [26] Copyright (2018), Elsevier [27,28], Reprinted with permission from [29]. Copyright (2019), American Chemical Society [30].

\section{Electrochemical Biosensors}

Biosensors that convert highly specific biologic information into electrical signals are an attractive tool in remote healthcare monitoring. Electrochemical biosensors were one of the earliest biosensor platforms to revolutionize wearable technology, as they use a fairly simple sensor setup and hence are cost efficient [31]. These benefits are associated with large-scale, low-cost electrical microcircuit production along with technology that allows easy readouts and data processing in these biosensors [31]. In addition, electrochemical biosensors have robust detection limits; even with limited analyte volume, they can produce accurate measurements due to their high specificity and binding affinity with the bioreceptors (e.g., enzyme-substrate or antigen-antibody interactions). These reactions, when converted into electrical signals, typically generate measurements as either (a) a current (amperometric), (b) a voltage or potential (potentiometric), or (c) a difference in conductivity of the electrolyte (conductometric) [32]. Other detection techniques described in the literature include impedimetric techniques, which combine both resistance and reactance [33] and the use of transistors to measure the current due to the potentiometric effect on the electrodes [31,34]. The most significant component of electrochemical biosensors is the electrode that holds the bioreceptor of interest. Therefore, it is crucial to employ a biocompatible and functional yet supportive material for their fabrication that allows for proper orientation, immobilization, and detection of analytes [35]. To fulfill these objectives, a variety of materials are tested across the labs to develop biosensors with the best performance. More insights on the available materials and their modifications are discussed under Section 7 (Material Considerations for Wearable Biosensors). In this section, we will mainly focus on the most recent developments in the field of electrochemical wearable biosensors and critically evaluate the possible future applications, and discuss the limitations that need to be overcome for their successful commercialization.

As described previously, depending on the type of analyte, different biosensing mechanisms and interfaces are used for their detection. Lei et al. (2019) described an MXene-based non-invasive, multifunctional, wearable sensor that uses a highly selective screening panel of biomarkers present in sweat [36]. They used a $2 \mathrm{D}$ MXene $\left(\mathrm{Ti}_{3} \mathrm{C}_{2} \mathrm{~T}_{\mathrm{x}}\right)$ Prussian blue (PB) 
composite electrode design that has superior conductivity and electrochemical detection due to the solid-liquid-air tri-phase interface that combines with a hydrophobic substrate. The design of the biosensor is unique, as the tri-phase allows for better oxygen supply and thus increased stability of the sensor (Figure 3A). The sensors are designed to detect three main analytes: glucose, lactate, and $\mathrm{pH}$ levels, and the measured $\mathrm{pH}$ values are calibrated and plotted against the glucose and lactate concentrations to determine final results. They also conducted an in-vitro perspiration test on a human subject by connecting the wearable patch to an electrochemical analyzer and successfully measured the glucose, lactate, and $\mathrm{pH}$ changes during an intensive cycling session before and after meals. Results from this study show a promising wearable device with high performance owing to the 2D morphology and superior conductivity of the MXene/PB composite, stretchable and skinintegrating design of the patch with better oxygen supply, and the ability to analyze three different parameters simultaneously [36]. However, the fabrication and assembly of such a multiphase, multifunctional device might pose a challenge in terms of cost and commercial dissemination. In the same line, Yang et al. (2019) used a polyethylene terephthalate (PET)based gold electrode (PGE) to develop an electrochemical sensor that also uses sweat as an analyte to detect glucose levels [37]. They used a UV-based chemical plating technique with a simple, cost-efficient, and easy-to-assemble sensor platform with a reliable amperometric output and high glucose sensitivity. This strategy overcomes the limitations of the previous generation of PET-based sensors that used a complex fabrication process and expensive techniques like photolithography and oxygen plasma etching, among others [38]. They also tested the efficiency of the PGE sensor with commercial glucose detection assays in testing sweat samples and observed comparable glucose concentrations [37]. Recently, an advanced, self-powered, sweat-based glucose-monitoring smartwatch was reported by Zhao et al. The smartwatch used flexible photovoltaic cells and batteries attached to a strap to generate a real-time, dynamic display of sweat glucose levels [39]. However, the complexity in designing a smartwatch with self-powering technology not only requires successful assembling of sensitive sensors and integrated display but also should align with current fashion trends while considering the cost. Lactate is another key bioanalyte used for fabricating electrochemical sensors due to its unprecedented role in monitoring several physiological and disease states.

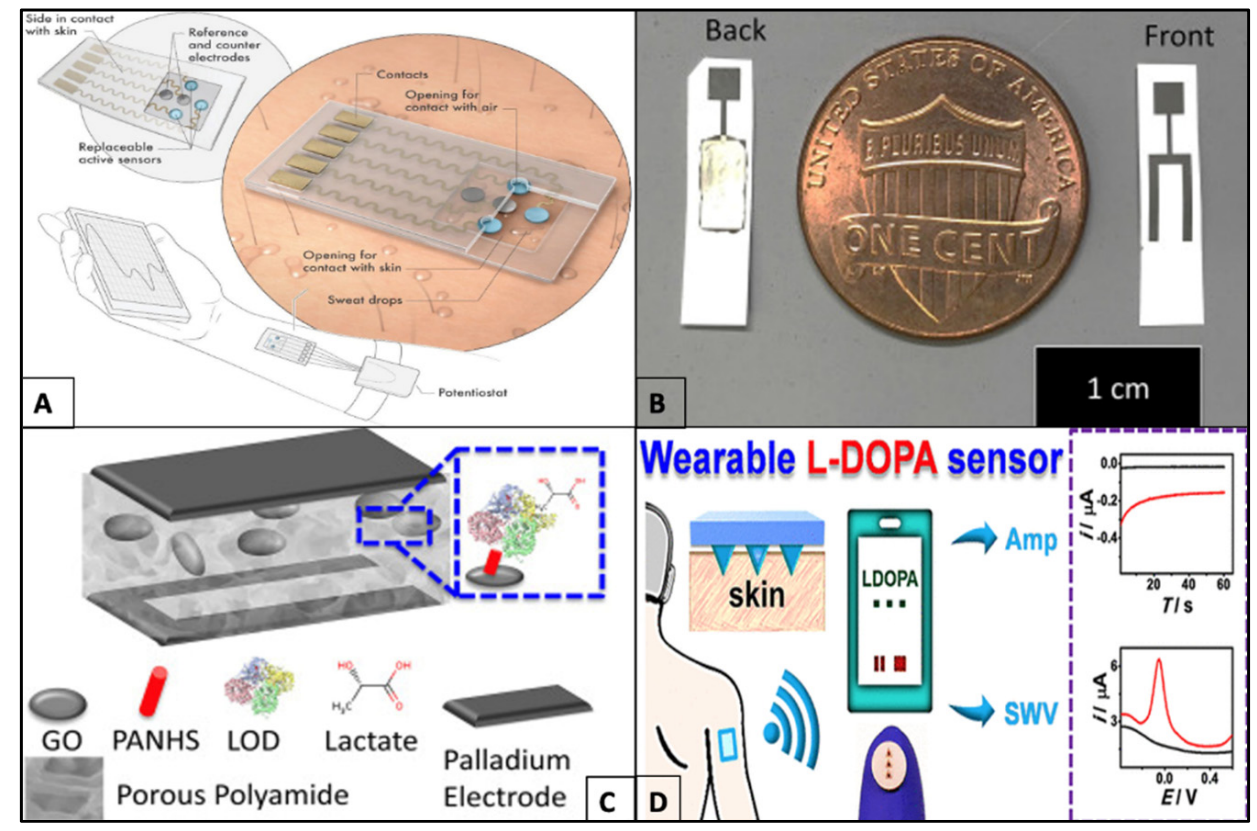

Figure 3. Examples of wearable electrochemical sensors. (A) Schematic illustration of the 2D MXenebased sweat sensor system showing the arrangement of electrodes, sweat uptake system, and sensors 
in contact with skin along with on-top openings for a sufficient supply of oxygen. Images reprinted with permission from [36], Copyrights (2019), John Wiley and Sons. (B) Image of a flexible graphene oxide (Flex-Go) biosensor in comparison to the size of a coin. (C) Schematic representation of the Flex-Go biosensor showing the electrodes (top-palladium and bottom-porous polyamide) with graphene oxide nanosheets embedded in between, along with 1-pyrenebutyric acid-N-hydroxysuccinimide ester (PANHS) and lactate oxidase (LOD) to detect lactate from sweat samples. Image reprinted with permission from [40], Copyrights (2021), Elsevier. (D) Schematic representation of a microneedle-based wearable patch for L-dopa detection from interstitial fluid (ISF) transmitting data to a wireless portable electrochemical analyzer sensed using square wave voltammetry (SWV) and amperometry. Reprinted with permission from [41]. Copyright (2019), American Chemical Society.

Recently, Lin et al. (2020) developed a flexible graphene oxide (Flex-Go)-based biosensor for electrochemical lactate monitoring with sweat volumes as low as 1-5 Ul [40] (Figure 3B,C). Their research outcomes demonstrated that the dynamic range of a lactate biosensor is between 1-100 mM, which corelates to the physiological lactate levels in sweat and with comparable performance to their biosensor with a commercially available Lactate Plus meter [40]. However, although they established a benchmark for small-volume analyte detection, there are still several challenges that need solutions in terms of modulating the $\mathrm{pH}$, dielectric strength, and conductivity of body electrolytes analyzed prior to focusing on the mass production and disposition of these wearables. Similar studies using lactate detection in sweat were performed by Wang et al. (2020) and Zhang et al. (2020), where both teams focused on developing flexible, non-invasive electrochemical sensors [42,43]. The Wang group developed a stretchable gold-fiber-based sensor integrated into a wearable textile that combined the high biocompatible, conductive properties of gold with superior lactate sensitivity in addition to high resistance against tensile strain [42]. Zhang et al., on the other hand, proposed the use of Ag nanowires (AgNWs) and molecularly imprinted polymers (MIPs) and showed the novelty by showing high detection limits of lactate of up to $0.22 \mu \mathrm{M}$ in addition to reliable electrochemical response and stable electrode structure that can withstand repeated bending and twisting forces [43]. Despite their mechanical properties, compliance with the skin surface, and ease of mountability, they are still for proof of concept, but under appropriate technological guidance and marketing can pave the way to real-life applications.

Electrochemical sensors have recently seen increased growth as a drug-screening platform from body fluids, both for therapeutic and drug abuse. Barfidokht et al. (2019) developed the first "Lab-on-Glove" concept for rapid on-site detection of fentanyl with an electrochemical sensor integrated into the glove fingertips. The glove design utilizes the thumb to collect drug residues along with the index finger, which has printed carbon electrodes with an ionic liquid carbon nanotube composite film [44]. Voltametric outputs are generated on joining the thumb and index fingers, closing the electrical circuit, which results in anodic peaks that correspond directly to fentanyl oxidation levels. A similar strategy using carbon-based screen-printed electrodes (SPEs) has been used for other forensic applications, as they are cheap, disposable and have good compatibility with several electrochemical analyzers [45]. Several authors have used this technique to detect cocaine from body fluids and samples by targeting tertiary amine moiety of cocaine, which requires no incubation and has a rapid response [46-48]. Carbon-paper electrodes, including molecularly imprinted ones, have been widely used to develop electrochemical sensors for tetrahydrocannabinol (THC) sensing [49,50]. However, most of these sensors used for drug-abuse detection are still more focused on the "sensitivity" aspect of the assembly than the more futuristic wearable translation. Several electrochemical biosensors are gaining attention for use as therapeutic drug monitoring (TDM) to improve the pharmacokinetics of drugs with sensitive therapeutic ranges and poorly understood target doses. Takeda et al. (2020) developed a single-use, ceramic-based MIP using a carbon-paste electrode for monitoring drugs, including vancomycin, meropenem, theophylline, and phenobarbital. The 
relationship between drug concentration and response current was obtained using differential pulse voltammetry (DPV) [51]. Although the sensor was not fully non-invasive, owing to the requirement of blood as a sample to detect the drug of interest, their results suggest an efficient, cost effective, sensitive biosensor for remote (bedside) drug monitoring with minimal assistance. An example of a minimally invasive wearable electrochemical biosensor for monitoring levodopa was described by Goud et al. (2019). The multimodal microneedle patch works on two simultaneous parallel reactions: the enzymatic-amperometric and nonenzymatic-voltametric detection of L-dopa [41] (Figure 3D). Such a biosensor with superior analytical performance not only provides dynamic, accurate results due to its multidimensional data acquisition and processing, but also has potential to work with skinlike surfaces based on the results of tests on mouse-skin surfaces [41]. Such an orthogonal microneedle-sensing platform can be used for the detection of other biomarkers in interstitial fluids if the patch design is optimized to perform similarly on human skin. "The Lancet Digital Health" published in 2019 the first in-human evaluation of a microneedle-based biosensor for monitoring phenoxymethylpenicillin [52]. This proof-of-concept study tested real-time TDM in 10 healthy volunteers and concluded that a microneedle beta-lactam biosensor is highly effective and tolerated by healthy individuals. Evidence also shows that the pharmacokinetic profiles of phenoxymethylpenicillin were similar in microdialysis and microneedle methods. This study facilitates future research on microneedle ECF as a cornerstone in antibiotic drug monitoring. Although most of these studies show remarkable advances in terms of device form, flexibility, and well-integrated sensing modules, there are some noteworthy barriers that limit their application. We have yet to utilize the wide potential of new biomaterials used to develop these sensors due to lack of effective ways to fabricate and tune them to our needs. In addition, to utilize the potential of each material under various situations, we trail years of research in order to translate their use for health-monitoring purposes. More importantly, once these challenges are overcome, research focus should then be pointed towards making them safe to use, wear-resistant, and reusable, and possibly recyclable to meet the environmental regulations set in the future.

\section{Electromechanical Biosensors}

An electromechanical biosensor works quite similarly to an electrochemical sensor in terms of the sensing principle; however, it varies in terms of how the electrical response is generated, which is chiefly due to a mechanical force or alternatively the strain recorded due to an electrical bias. A significant advantage of this type of transduction as opposed to electrochemical and optical sensors is the lack of dependence on the labeling of molecules. This can allow for the identification and quantification of a wide range of biomolecules, including unknown ones without the concern of lack of sensitivity or degree of analytebioreceptor interaction. Skin or epidermis is a soft and stretchable surface, and thus one of the most important mechanisms dictating the functioning of mechanical biosensors is their ability to sense the physical changes occurring on the skin surface at a macroscale, like arm, wrist, or leg movements or changes as small as a stretch or dampening of the epidermis like while breathing [53]. The electromechanical transduction mechanism is usually based on either (a) piezoelectric, (b) piezoresistive, (c) piezocapacitative, (d) iontronic, or I triboelectric nanogeneration (TENG) effects [8,54] (Figure 4). 


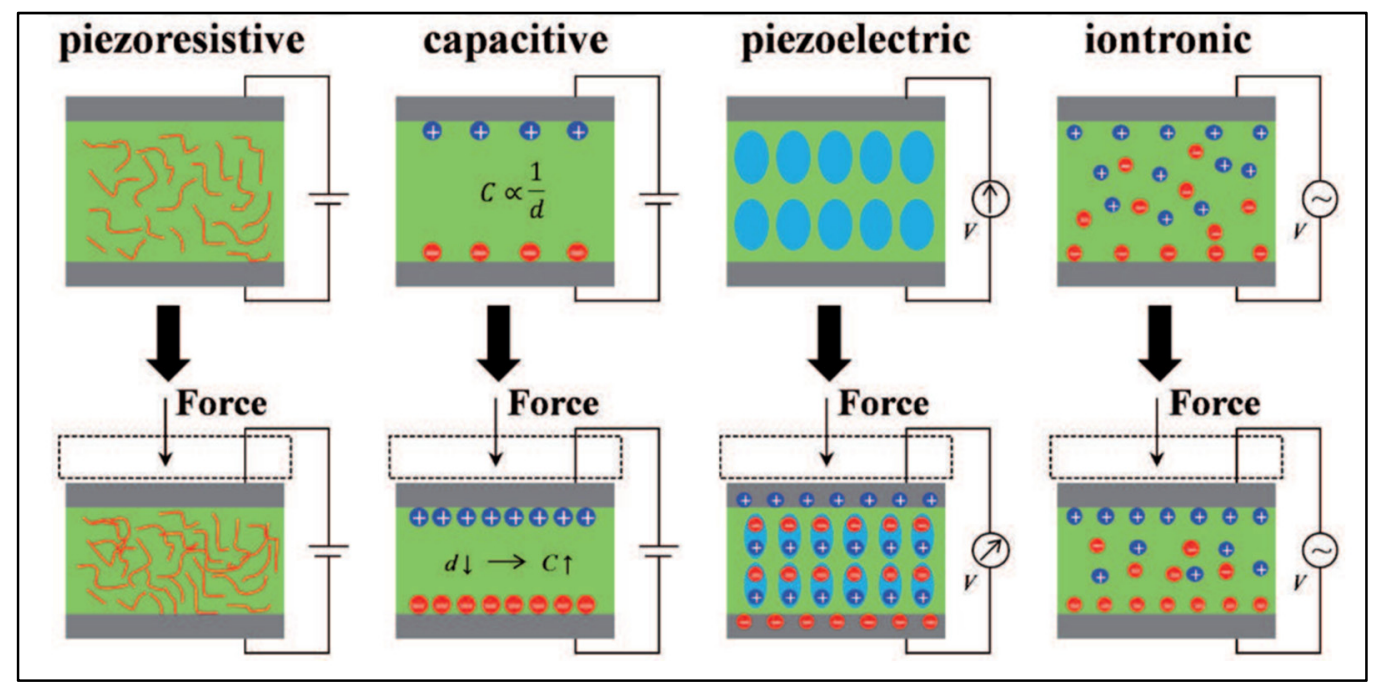

Figure 4. Schematic diagram showing different types of electromechanical transduction mechanisms. Image reproduced with permission from [8] Creative Commons Attribution 3.0 License.

Strain sensors function by quantifying mechanical deformation with corresponding changes to the electrical signals, which can be either piezoelectric (captures changes in surface potential due to polarization) or piezoresistive (captures changes in resistance caused by external forces) [53,55]. Capacitive sensors have superior sensitivity and react to changes in capacitance due to forces causing geometrical deformations; however, they are affected by surrounding noise, which may influence their performance [56]. Iontronic sensors utilize a supercapacitance platform that is about 1000 times larger than a metal oxide capacitor platform by forming an ion-electric interface between the electrodes and electrolytes, leading to ion accumulation on the electrodes and high capacitance per unit area [8]. Triboelectric transduction utilizes the simple principle of frictional charges that results from the interaction of two different materials. This was the principle used for the development of the TENG by Fan et al. (2012) [57]. When the friction is interrupted, the separation of the surfaces produces a difference in potential that is often used to develop sensors without use of external power [58]. Stretchable strain sensors require a high gauge factor to detect these minor movements, which occur on irregular skin surfaces and hence need to be designed with flexibility along with functionality. For example, Tang et al. (2020) designed a strain biosensor based on aligned nanowire with a high surface-to-volume ratio to monitor subtle human motion [59]. They were able to achieve a gauge factor of nearly 35.8 with the ability to detect a stimulus of a deformation of less than $200 \mu \mathrm{m}$ in under $230 \mathrm{~ms}$. The results were five times better when compared to a similar biosensor using microwire-based sensors [59]. In another study, Wang et al. (2020) created a stretchable ion-based sensor based on the surface strain redistributed elastic fiber (SSREfiber) that uses a wrinkle structure to improve surface area along with an island bridge design [60]. Although this principle does not use an electromechanical mode of sensing, the minimized strain on large amounts of stretching makes the SSRE platform an excellent choice for a textile-based wearable biosensor. Textile-based mechanical biosensors are an attractive tool in human motion detection and pave the way for personalized healthcare by functioning analogously to how we choose an outfit that conforms to our physical attributes. However, it is still a challenge, as such a technology would require the fabric to be highly conductive and equally resistant to strain. Usually, carbonization is the first line of choice to improve conductivity in textiles either by dip-coating, vacuum filtration, or the addition of metal nanoparticles [61-65]. Such an example of a wearable biosensor was developed using commercially available spandex by Yang et al. (2020), wherein they dipped the polyamide into carbonic pigment inks to fabricate a high-fidelity, conductive strain sensor [66] (Figure 5). Their work points to the potential application of these smart textiles by (i) mounting them to different joints (fingers, wrist, arm) to collect pulse rates, 
(ii) printing or sewing the strain sensors onto fabrics to capture functions like breathing and respiration, or (iii) utilizing them to generate protective devices for monitoring joint movements in sports medicine and posture-related diseases like Parkinson's [66].

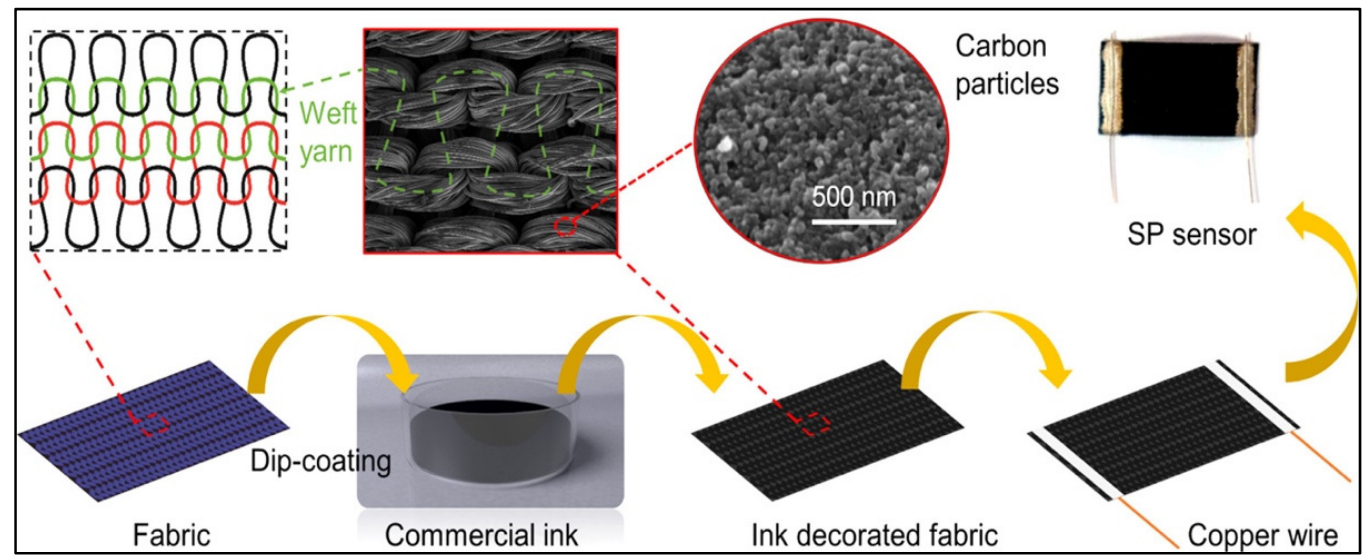

Figure 5. Schematic illustration of the fabrication process of an ink-decorated fabric strain sensor. First, the fabric is washed three times with deionized water, followed by dip coating in commercial ink, which is absorbed and dried in an oven at $60^{\circ} \mathrm{C}$ for $1 \mathrm{~h}$. Next, two copper wires are mounted onto the two ends of the fabric strip using silver paste to improve integration, which is dried again and ready for use with textiles. Reprinted with permission from [66]. Copyrights (2020), American Chemical Society.

Tactile sensors, on the other hand, use the same transduction mechanisms but are fabricated to respond to external stimuli like pressure, touch, force, etc. [67]. These sensors are able to maintain their functional properties both in the native form and under deformation, which is mainly due to the bending (deflection) abilities and the high shape memory in response to multiplanar strains [67]. Our routine physiological response releases signals to the skin surface ranging from low frequency $(\sim 0.1-1 \mathrm{~Hz})$ for respiration, facial expressions, and hand gestures to high-frequency acoustic signals (10-100 Hz) for speech and heart movements, utilizing the skin-air interface [68-70]. Jang et al. (2020) did a comprehensive update on pressure and tactile sensors for motion detection using field-effect transistors (FETs), which utilize the advantages of collecting and processing data in an array rather than individual sensors, allowing for high uniformity and spatial contrast to improve gesture recognition [71]. Such sensing mechanisms are essential to locate and collect large amounts of data from micro-expressions and split-second movements that occur on skin and superficial muscles and find key applications for the clinical diagnosis of several medical conditions. Ozioko et al. (2020) developed a piezoresistive wearable assistive tactile communication interface with vibrotactile feedback based on finger braille, a tactile communication platform used by deafblind people [72]. This work overcomes many challenges portrayed in the previous work on tactile braille-based communication where the sensors and actuators are isolated, making it difficult for users to interpret messages. The sensor showed maximum stability at $2.5 \mathrm{~Hz}$ cyclic loading, whereas the actuator can provide uniform vibrations with input signals of frequencies ranging from $10 \mathrm{~Hz}$ to $200 \mathrm{~Hz}$, making the user feel and distinguish between messages [72]. On a different spectrum, pressure sensors are being widely used for applications in biomedical monitoring. Qi et al. (2020) reported the use of a core-sheath nanofiber yarn-based textile pressure sensor with superior sensitivity of $16.52 \mathrm{~N}^{-1}$, a wide sensing range $(0.003-5 \mathrm{~N})$, and rapid response time ( $\sim 0.03 \mathrm{~s})$ [73]. These properties will allow such pressure sensors to integrate into skin surfaces to accurately monitor human movements, from pulsations to tremors and high-intensity activities. Similar studies were reported elsewhere by Yi et al. (2021), wherein they used an all-3D-printed, flexible, and wearable hybrid bioelectronic tactile sensor fabricated using biocompatible nanocomposites. They show comparable 
results to the previously discussed studies with advantages of low detection limits, quick response rates, excellent biocompatibility, better compressibility, and a matching modulus of elasticity with human skin [74]. Developments in strain and tactile sensors have a multitude of applications, like monitoring general physical health, social interactions, assistance to specially abled populations, improving athletic performance and rehabilitation, and measuring sleep quality, among other applications. However, the human body releases an array of mechanical and/or acoustic signals for each action or physiological function, which sometimes occur simultaneously and are often superimposed, making it challenging to compute such high-frequency data signals. Although newer approaches like machine learning and advanced algorithms seem to overcome some of these concerns, the practical application and scope of wearable tactile sensors still requires a multimodal recognition approach to engineer precise gesture-control systems.

\section{Optoelectronic Biosensors}

Optical biosensors detect or respond to analytes by undergoing optical changes like absorption, emission, reflection, refraction, or an interference [75]. These optical signals supersede the previously discussed physico-mechanical signals for transduction in terms of their high sensitivity, low noise, fewer surrounding disturbances, and long-term stability [76]. These advantages have led to several significant studies of applications in the field of diagnosis and drug discovery, health, and environmental monitoring [76,77]. In terms of optical transduction, sensor performance (sensitivity) is evaluated in terms of light-matter interaction, which corresponds to changes in optical signals and analyte changes. A large number of these biosensors exploit the evanescent wave phenomenon and can be routinely seen as a principle used in SPR-based biosensors (discussed in the next section), where they detect the changes in the refractive index on the sensor surface and appear as a shadow angled from the surface, depending on the mass of the material [78]. One of the main considerations while fabricating such optical biosensors is to focus on the biofunctionalization of the receptor on the sensor surface, which requires proper immobilization techniques for successful detection $[79,80]$. Usually, the first step in biofunctionalization is the cleaning of the sensor surface; next is the chemical activation of sensor surface; and third is the immobilization of the known specific biorecognition element, followed by the final detection stage, when target molecule attaches to the receptor (Figure 6). The immobilization may occur by simple physical adsorption, covalent bonding to the biomolecule, non-covalent or electrostatic interactions, or physical entrapment $[81,82]$.

Several types of optical detection methods are described in the literature, but it is outside the scope of this review to detail them all. Thus, in this section, we will mainly discuss the most recent developments in SPR biosensors with potential remote healthcare applications, wearable fiber-based label-free and photoplethysmography (PPG)-based optical biosensors. 

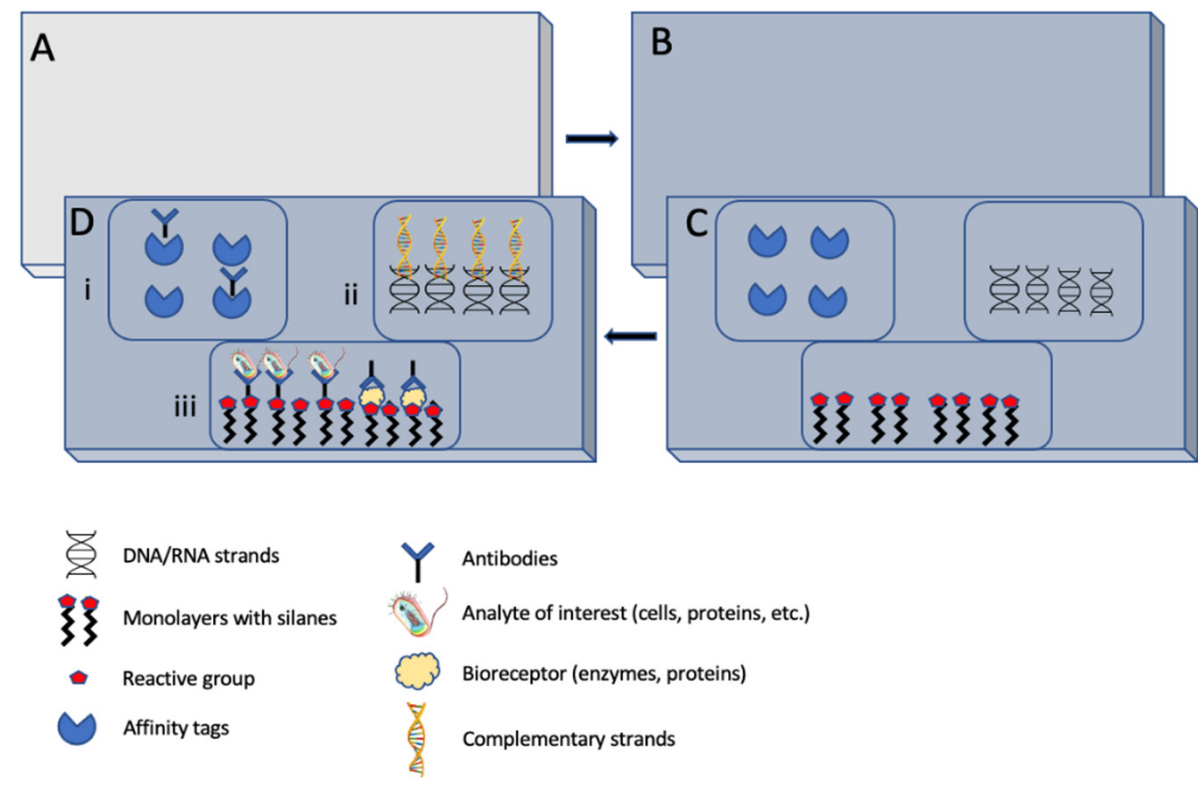

Figure 6. Schematic illustration of key biofunctionalization strategies for the fabrication of optical biosensors. (A) Cleaning of biosensor surface (grey surface). (B) Chemical activation of sensor surface (blue)—commonly used materials include silicon, its oxides, or nitrides, which use the silane chemistry to functionalize high-class optical transducers. (C,D) (i) Immobilization of bioreceptors on the treated surface, which can be affinity tags like protein A, a streptavidin biotinylated surface that attaches to selective antibodies; (ii) covalent immobilization (DNA-/RNA-based probes), which reacts with complementary strands; (iii) self-assembled monolayers with organosilanes to react with specific antibodies for covalent-based protein or analyte detection or hydrophilic monolayers with pegylated silanes or dextran-based molecules with covalently immobilized proteins for antibody detection. Image adapted with permission from [81], Copyrights (2011), John Wiley and Sons.

\subsection{SPR-Based Optical Sensors}

The past decade has seen tremendous growth in label-free SPR-based biosensor technology for biomarker detection and discovery due to its rapid, accurate, and versatile mode of action [83]. SPR is said to be the gold-standard transducer in the detection of several key biomarkers of heart disease, cancer, viral and bacterial antibodies, markers of hormonal regulation, renal function, and liver disease $[84,85]$. Although this technology has existed for decades, advancements in nanomaterials and fabrication strategies have seen newer sensors with enhanced sensitivity and a range of applications. Some SPR sensitivity improvements have been discussed recently [86-89]. Glucose monitoring has been quite successfully achieved using optical biosensors, as with the previously discussed electro-chemical and mechanical biosensors, and has been recently investigated by Zhang et al. (2021) [90]. However, this is achieved in a rather non-invasive and self-assisted manner with the optical transducers. Koushki et al. (2020) investigated the efficiency of optical glucose sensing in saliva using the SPR effect on gold nanoparticles (AuNPs) with a 10-13 nm diameter. They tested the effect of glucose and glucose oxidase (GOD) on the UV-vis spectrum of AuNps by either adding glucose solution to AuNps, followed by the addition of GOD or by the addition of glucose and GOD simultaneously, and measured the optical properties of both solutions. The glucose concentration in the tested solutions followed the sugar levels present in normal saliva [91]. The study concluded that the AuNP diameter is a key aspect in modulating SPR values, which suggests high glucose detection accuracy. These results can open potential applications of plasmonic nanometals in wearables like mouthguards and retainers for self-monitoring glucose levels in diabetic patients. On a similar note, with the aim of improving optical glucose detection, Yadav et al. (2020) did 
a comparative study by angle modulation for reflectance values in metamaterial (MM) SPR and $\mathrm{SiO}_{2}$-based SPR (Si-SPR) by fixing the wavelength and thickness constant [92]. They used urine samples to detect the sugar levels and found that the reflection dip angle varies between the urine of diabetic and non-diabetic patients with an angle of incidence at 50.7 and $60.1 \mathrm{deg}$ between nondiabetic MM-SPR and Si-SPR. They further discovered the reflection angle to be different for diabetic patients with varying sugar concentrations. These data suggest progress towards the development of optical biosensors with specific sensor-surface modifications personalized to patients with different types of diabetic value ranges. More recently, Mostufa et al. (2021) developed a graphene-coated SPR biosensor for the detection of hemoglobin and glucose levels in blood and urine samples, respectively. The multilayered sensor was built with an initial layer of prism $\left(\mathrm{BK}_{7}\right)$, followed by gold, a transition-metal dichalcogenide (TMDC) layer of $\mathrm{PtSe}_{2}$, and lastly, graphene (Figure 7A). Upon placing blood samples on the sensing layer, hemoglobin levels were detected by a 0.001 variation in a refractive index proportional to $6.1025 \mathrm{~g} / \mathrm{L}$ hemoglobin in the sample. These values were used for analysis using COMSOL Multiphysics software and plotted using MATLAB software. Urine samples were analyzed by monitoring the SPR angle shift, and for a 0.001 refractive index change, the angular shift sensitivity was found to be $200 \mathrm{deg} /$ RIU [93]. This multilayered-multianalyte detection SPR-based sensor can pursue a practical application in the bedside, remote monitoring blood hemoglobin levels and urine glucose simultaneously. A combination of 2D photonic crystal fiber (PCF) with SPR was developed by Mitu et al. (2021) for pregnancy testing by analyzing pregnant urine samples [94]. The approach was similar to the previous study using the finite element method (FEM) to numerically calculate the refractive indices, sensitivity, and resolution. Although SPR-based optical transducer modification and combinations have seen potential application in sensing applications, there is still a long way to go before making these advanced technical modifications into practical wearable sensors for remote healthcare monitoring.

\subsection{Optical Fiber-Based Biosensors}

There is a constant growth in fiber-optic technology across the industry and healthcare $[95,96]$. They have several merits, like compact size, low weight, immunity to electromagnetic radiation, robust and safe mode of action, superior sensitivity, and precision to function as wearables, among others $[97,98]$. These intrinsic characteristics of optical fibers have been well exploited by the developing wearable biosensing paradigm. Medical monitoring is the field that has benefitted the most due to this surge of interest and a great number of studies ae now focused on fiber-optic wearables.

Several commercial products have been developed, and many proof-of-concept studies have been conducted-for example, Li et al. (2020) devised an optical fiber-based, wrist-wearable, continuous and accurate blood-pressure monitor fabricated using a polydimethylsiloxane (PDMS) + Ag composite diaphragm and tested its functionality in 17 clinical subjects. The phase variation of the light reflected from this diaphragm surface was used to measure the blood pressure from the radial arterial pulse. The blood pressure values were obtained using the pulse transmit time (PTT), which was derived from the pulse waveform. On comparing the results with a routine sphygmomanometer, they found an error of $0.24 \pm 2.39 \mathrm{mmHg}$ and $0.12 \pm 2.62 \mathrm{mmHg}$ in the systolic and diastolic blood pressure, respectively, which is an acceptable variation in commercial BP monitors [99]. The proposed wrist band with optimized wearable design and display can work as a simple economic version compared to expensive smartwatch brands, and is a user-friendly device to continuously monitor BP and can replace current available commercial devices. Optical fibers using impact-detection systems usually use either a distributed or quasi-distributed approach to assess disturbances, and do so in the range of kilometers [100]. Distributed detection systems are either based on optical time-domain or optical frequency-domain reflectometry and are considered to have lower spatial resolution due to large distance range, in addition to expensive and nonportable components for sensor fabrication [101]. 
The quasi-distributed system, on the other hand, is based on the fiber Bragg gratings (FBGs) and provides a better spatial resolution due to shorter distance range, as low as centimeters between the FBGs, but still remains commercially inapplicable due to its bulky nature.

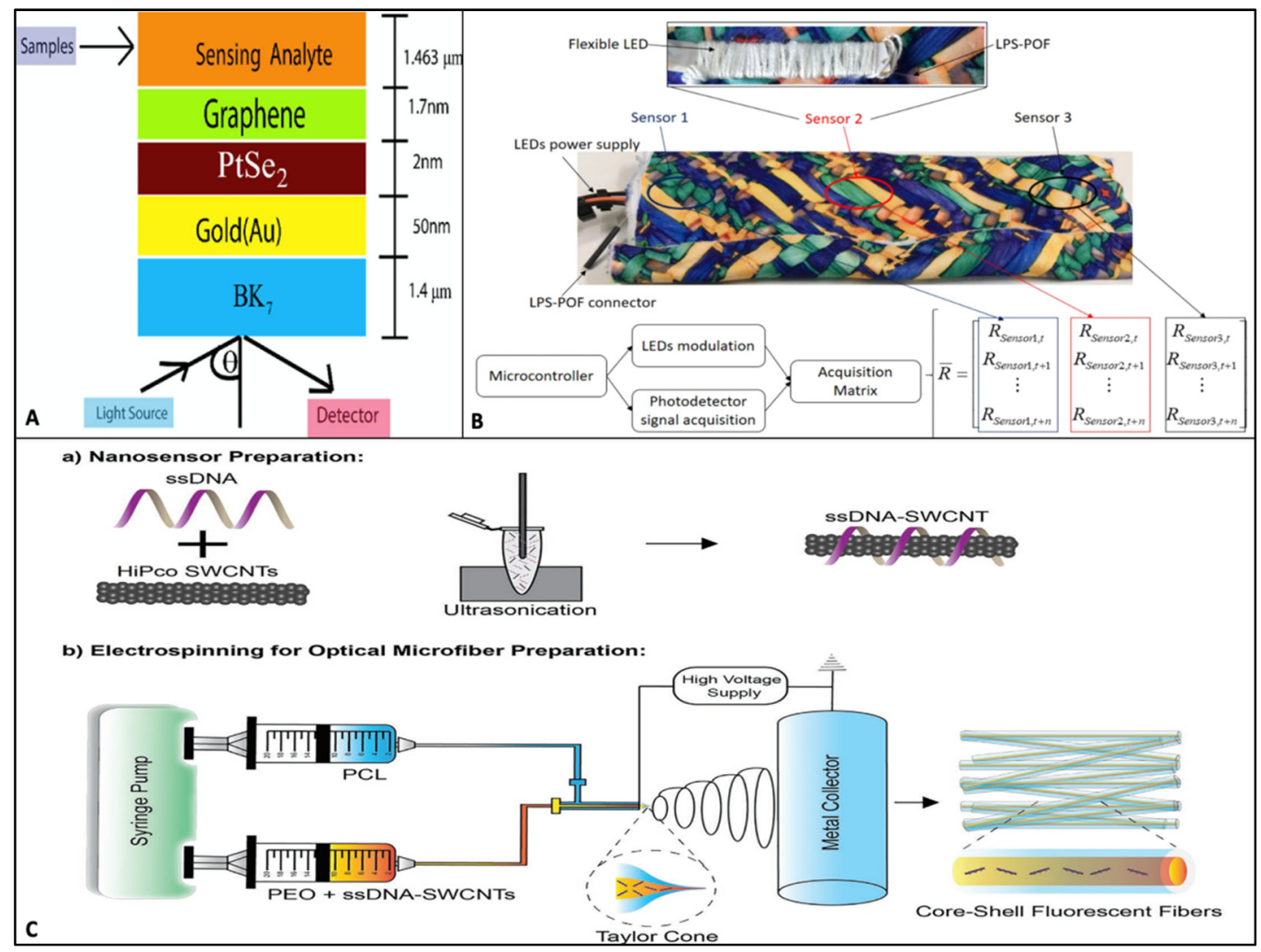

Figure 7. Optical biosensing technologies. (A) Schematic illustration of the multilayered SPR sensor made of $\mathrm{BK}_{7} / \mathrm{Au} / \mathrm{PtSe}_{2} /$ graphene layers for monitoring blood $\mathrm{Hb}$ and urine glucose levels. A monochromatic light source with a wavelength of $628.8 \mathrm{~nm}$ is applied to $\mathrm{BK}_{7}$ with a 60 deg to $89 \mathrm{deg}$ angular range and the detector measures the sensor sensitivity based on the shifting of dip in reflectance intensity (\%) based on variation in the refractive indices of blood and urine samples. Image reproduced with permission from [93], Copyrights (2021), Optical Society of America under the terms of the OSA Open Access Publishing Agreement. (B) Photographic representation of the multifunctional smart textile showing the LPS-POF sensor placement and schematic representation of the acquisition matrix due to sensor responses. Image reproduced with permission from [102], Copyrights (2020), Springer Nature. (C) Fabrication of optical microfibers: (a) Preparation of aqueously dispersed single-stranded DNA-single-walled carbon nanotubes (ssDNA-SWCNTs) by probe-tip sonication of SWCTs in the presence of ssDNA; $(\mathbf{b})$ core-shell electrospinning setup for the fabrication of optical microfibrous textiles. Image reproduced with permission from [103], Copyrights (2021), John Wiley and Sons.

An alternative to this impact-based detection was proposed by Leal Junior et al. (2020) using transmission-reflection analysis (TRA) to develop a fully portable, wearable smart garment. Magnesium- and erbium-coated optical fibers in the sensor improve the challenges in spatial resolution reported previously due to low Rayleigh scattering when using single-mode fibers (SMFs) by increasing the Rayleigh scattering and, in turn, causing higher backscatter and better spatial resolution in TRA systems. Based on this approach, they developed a nanoparticle optical fiber (NPF)-integrated smart textile, which, along with TRA, allows for simultaneous detection of perturbation and fiber displacement due to external forces [104]. This is an excellent approach to developing a compact, portable system with low electromagnetic interference for continuous gait or natural posture monitoring in patients with movement or gait dysfunctionalities. The same group, Leal Junior et al. 
(2020), reported on the development of a multiparameter, quasi-distributed smart textile using highly stretchable polymer optic fiber (POF) fabricated using the light polymerization spinning (LPS) approach (Figure 7B). The textile was made of neoprene fabric comprised of LPS-POF along with three light-emitting diodes (LEDs) to sense variations in temperature, transverse force, and angular displacements [102]. The multiplexed sensor is capable of monitoring more than one parameter while maintaining its stretchable properties due to the LPS fabrication technique allowing for accurate movement detection without affecting the range of movements. More recently, Safaee et al. (2021) showed the fabrication of an optical core-shell microfibrous textile material incorporated with single-walled carbon nanotubes (SWCNTs) for real-time monitoring of reactive oxygen species (oxidative stress) in wounds by tracking the hydrogen peroxide concentration in wounds (Figure 7C). The SWCNTs have fluorescent properties that allow for continuous monitoring of oxidative species without succumbing to decay of signals [103]. Their application in textiles will allow for novel wound-dressing fabrics with the ability to monitor healing without degradation in optical properties. A similar stretchable, wearable, ultrathin sensor was developed by using a wavy optical microfiber by Zhu et al. (2021) using the bottom-up approach and was capable of successfully monitoring BP via wrist pulses [105]. Some other optical microand nanofiber-based wearable optical sensors used for monitoring respiration and bodily movements can be found in these papers [106,107].

Fiber-free optical sensing and detection systems exist, including near-infrared spectroscopy to probe skin tissues to measure and analyze tissue oxygen saturation and blood flow $[108,109]$. A pulse oximeter is one such device, which is a non-invasive optical sensor working on the photoplethysmogram (PPG) technique used for blood volume $(\mathrm{Hb})$ and blood oxygen $\left(\mathrm{HbO}_{2}\right)$ changes $[110,111]$. In simple terms, the oximeters function by using two wavelengths of adequate path lengths to differentiate between absorption peaks of $\mathrm{Hb}$ and $\mathrm{HbO}_{2}$. Using this difference, measured as the ratio of light absorbed by each factor, the concentration or saturation of $\mathrm{Hb}$ and $\mathrm{HbO}_{2}$ is determined by the Beer-Lambert law [111]. A comprehensive literature review on the current developments in PPG-based label-free optical biosensors was discussed by Dhanabalan et al., 2020 [84]. A recent literature search also uncovered the potential of PPG in accurate heart activity monitoring, which is a searing topic among researchers for its use in remote evaluation of cardiac health. Recently Boukhayma et al. (2021) designed an earbud-embedded and a ring-embedded micro-powered millimeter-sized optical sensor for accurate heartbeat monitoring [112,113]. The monolithic optical sensor-based earbud uses a low-powered PPG chip fabricated in a $180 \mathrm{~nm}$ CMOS image sessor (CIS) with an area of $1.5 \mathrm{~mm} \times 1.5 \mathrm{~mm}$, which, due to the low dark current and noise, confers high sensitivity. The sensor module only utilizes a low $60 \mu \mathrm{A}$ current at $122 \mathrm{~Hz}$ frequency and enables a high signal-to-noise ratio of PPG with an LED current of less than $10 \mathrm{uA}$. The ergonomic earbud design was tested clinically in human subjects and the accuracy was compared to a commercial electrocardiogram (ECG), which showed a 98.47\% accuracy [112]. A similar module design strategy was employed to fabricate the ring-based sensor featuring the same quantum efficiency (QE) of $85 \%$, and the detection rate was $97.87 \%$ for $72.21 \mathrm{~h}$ for heartbeat monitoring compared to the ECG [113] (Figure 8A,B). The miniaturized structure and low-power, long battery-based ergonomic design paves the way for such technology to be translated into commercially available medical sensors for remote medical care. However, there are still missing pieces to the puzzle in terms of design optimization and cost-effective fabrication of these optical sensors, alongside the practicality of device support while translating this technology to the commercial market. In this past section, we discussed the examples of most recent advances made in electrochemical, mechanical, and optical wearable devices. Table 1. provides an overview of these examples based on the type of biomolecule used, platform of wearable device, material and transduction platform, in addition to their intended applications and current challenges. 


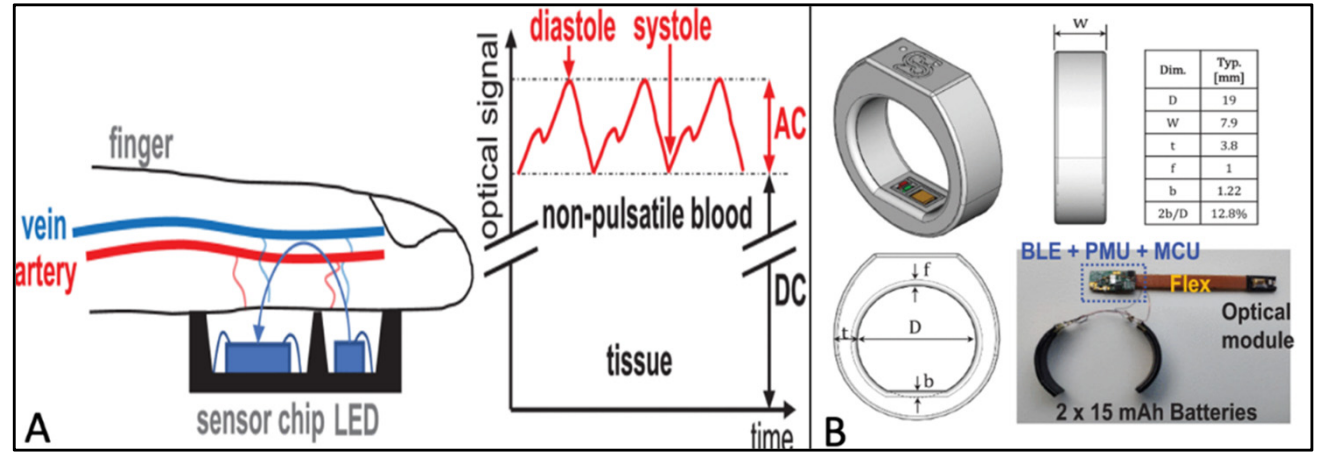

Figure 8. PPG-based optical wearables for heartbeat monitoring. (A) Schematic illustration of the sensor assembly for PPG measurement and the corresponding electrical components of the PPG signals. (B) Design of the ring at different views with a strapdown of the electrical module (right bottom); the top right shows the different parameters considered for superior ergonomics. Abbr.: low-energy Bluetooth (BLE), power-management unit (PMU), microcontroller (MCU), D (diameter), W (width), $\mathrm{t}$ (thickness), $\mathrm{f}$ (internal filleting radius), $\mathrm{b}$ (sensor position). Image reproduced with permission from [113], https:/ / creativecommons.org/licenses/by/4.0/, accessed on 26 November 2021.

Table 1. Selected examples of recently developed wearable biosensors.

\begin{tabular}{|c|c|c|c|c|c|c|}
\hline $\begin{array}{l}\text { Analyte, } \\
\text { Parameter }\end{array}$ & $\begin{array}{l}\text { Wearable } \\
\text { Platform }\end{array}$ & $\begin{array}{c}\text { Mode of } \\
\text { Transduction }\end{array}$ & Materials & Application & Challenges & Ref. \\
\hline $\begin{array}{c}\text { Glucose, lactate, } \\
\text { pH }\end{array}$ & Patch & Electrochemical & $\begin{array}{c}\text { MXene } \\
\left(\mathrm{Ti}_{3} \mathrm{C}_{2} \mathrm{~T}_{\mathrm{x}}\right) \text {-Prussian } \\
\text { blue }\end{array}$ & Sweat monitoring & $\begin{array}{l}\text { Fabrication and } \\
\text { assembly due to its } \\
\text { multiphase- } \\
\text { multifunctional } \\
\text { nature }\end{array}$ & [36] \\
\hline Glucose & Mountable chip & Electrochemical & $\begin{array}{c}\text { Polyethylene } \\
\text { terephthalate (PET) }\end{array}$ & Sweat monitoring & $\begin{array}{l}\text { Proof-of-concept study, } \\
\text { needs optimization and } \\
\text { validation to integrate } \\
\text { into wearables }\end{array}$ & [37] \\
\hline Glucose & Smartwatch & Electrochemical & PET & Sweat monitoring & $\begin{array}{l}\text { Complex design and } \\
\text { high cost of fabricating } \\
\text { smartwatch } \\
\text { components }\end{array}$ & [39] \\
\hline Lactate & Mountable chip & Electrochemical & Graphene oxide & Sweat monitoring & $\begin{array}{c}\text { Modulation of } \mathrm{pH}, \\
\text { dielectric strength, and } \\
\text { conductivity of } \\
\text { electrolyte and } \\
\text { integration of wearables } \\
\text { need validation }\end{array}$ & [40] \\
\hline Lactate & Textile-based & Electrochemical & Gold fibers & Sweat monitoring & $\begin{array}{l}\text { Textile shelf-life, fiber } \\
\text { displacement, cleaning } \\
\text { difficulties }\end{array}$ & [42] \\
\hline Lactate & $\begin{array}{l}\text { Skin-mountable } \\
\text { chip }\end{array}$ & Electrochemical & $\begin{array}{c}\text { Ag nanowires } \\
\text { (AgNWs) and } \\
\text { molecularly } \\
\text { imprinted polymers } \\
\text { (MIPs) }\end{array}$ & Sweat monitoring & $\begin{array}{l}\text { Still a proof-of-concept } \\
\text { study, needs validation } \\
\text { studies for } \\
\text { commercialization }\end{array}$ & [43] \\
\hline Fentanyl & Gloves & Electrochemical & $\begin{array}{c}\text { Printed carbon } \\
\text { electrodes with an } \\
\text { ionic liquid carbon } \\
\text { nanotube composite } \\
\text { film }\end{array}$ & Drug monitoring & $\begin{array}{c}\text { Main focus on drug } \\
\text { sensitivity, translation } \\
\text { to wearable design at } \\
\text { infancy }\end{array}$ & [44] \\
\hline $\begin{array}{l}\text { Vancomycin, } \\
\text { meropenem, } \\
\text { theophylline, } \\
\text { phenobarbital }\end{array}$ & Bedside monitor & Electrochemical & $\begin{array}{l}\text { Ceramic-MIP, carbon } \\
\text { paste electrodes }\end{array}$ & $\begin{array}{l}\text { Therapeutic drug } \\
\text { monitoring }\end{array}$ & $\begin{array}{c}\text { Partially invasive due to } \\
\text { drug monitoring in } \\
\text { blood }\end{array}$ & [51] \\
\hline
\end{tabular}


Table 1. Cont.

\begin{tabular}{|c|c|c|c|c|c|c|}
\hline $\begin{array}{l}\text { Analyte, } \\
\text { Parameter }\end{array}$ & $\begin{array}{l}\text { Wearable } \\
\text { Platform }\end{array}$ & $\begin{array}{c}\text { Mode of } \\
\text { Transduction }\end{array}$ & Materials & Application & Challenges & Ref. \\
\hline Levodopa & $\begin{array}{l}\text { Microneedle } \\
\text { patch }\end{array}$ & Electrochemical & $\begin{array}{l}\text { Tyrosinase modified } \\
\text { carbon-paste } \\
\text { microneedle } \\
\text { electrodes }\end{array}$ & Drug monitoring & $\begin{array}{l}\text { Lack clinical validation } \\
\text { and human skin } \\
\text { biocompatibility tests }\end{array}$ & {$[41]$} \\
\hline Beta-lactam & $\begin{array}{l}\text { Microneedle } \\
\text { patch }\end{array}$ & Electrochemical & $\begin{array}{l}\text { Polycarbonate } \\
\text { microneedles }\end{array}$ & $\begin{array}{l}\text { Therapeutic drug } \\
\text { monitoring }\end{array}$ & $\begin{array}{l}\text { Proof-of-concept study, } \\
\text { minimally invasive }\end{array}$ & {$[52]$} \\
\hline $\begin{array}{c}\text { Surface } \\
\text { deformation }\end{array}$ & $\begin{array}{l}\text { Mountable } \\
\text { sensor }\end{array}$ & Electromechanical & Aligned nanowires & Motion detection & $\begin{array}{l}\text { Proof-of-concept sensor, } \\
\text { needs integration into } \\
\text { wearable device }\end{array}$ & [59] \\
\hline Sodium & Textile-based & $\begin{array}{l}\text { Electrochemical- } \\
\text { mechanical }\end{array}$ & Ion-based SSRE-fiber & Sweat monitoring & $\begin{array}{l}\text { Lack of on-body trials, } \\
\text { needs optimization for } \\
\text { integration to textiles }\end{array}$ & {$[60]$} \\
\hline $\begin{array}{l}\text { Strain and } \\
\text { conductivity }\end{array}$ & Textile-based & Electromechanical & $\begin{array}{l}\text { Commercial spandex } \\
\text { and carbon ink } \\
\text { pigment-coated } \\
\text { polyamides }\end{array}$ & $\begin{array}{l}\text { Pulse rate, motion } \\
\text { detection, and } \\
\text { breathing }\end{array}$ & $\begin{array}{l}\text { Textile/coated ink shelf } \\
\text { life, cleaning, and } \\
\text { multistep fabrication } \\
\text { process }\end{array}$ & {$[66]$} \\
\hline $\begin{array}{l}\text { Vibro-tactile } \\
\text { feedback }\end{array}$ & $\begin{array}{l}\text { Finger-hand- } \\
\text { based }\end{array}$ & Electromechanical & $\begin{array}{l}\text { Velostat-polymer } \\
\text { impregnated with } \\
\text { carbon black }\end{array}$ & $\begin{array}{c}\text { Tactile } \\
\text { communication }\end{array}$ & $\begin{array}{l}\text { Lacks longitudinal } \\
\text { study to predict the } \\
\text { interface success }\end{array}$ & {$[72]$} \\
\hline $\begin{array}{l}\text { Pressure } \\
\text { sensations }\end{array}$ & Textile-based & Electromechanical & $\begin{array}{l}\text { Ni-coated } \\
\text { core-sheath } \\
\text { nanofiber yarn with } \\
\text { CNT-embedded } \\
\text { polyurethane }\end{array}$ & $\begin{array}{l}\text { Motion, pulse } \\
\text { detection }\end{array}$ & $\begin{array}{l}\text { Proof-of-concept design, } \\
\text { needs optimization and } \\
\text { validation for textile } \\
\text { integration }\end{array}$ & {$[73]$} \\
\hline Tactile sensations & Skin-mounted & Electromechanical & $\begin{array}{l}\text { 3D-printed } \\
\text { nanocomposites }\end{array}$ & Motion detection & $\begin{array}{l}\text { Proof-of-concept study; } \\
\text { needs miniaturization } \\
\text { to develop } \\
\text { skin-compatible, } \\
\text { compressible devices }\end{array}$ & {$[74]$} \\
\hline $\begin{array}{l}\text { Glucose, glucose } \\
\text { oxidase }\end{array}$ & In-vitro model & Optical (SPR) & Au nanoparticles & Saliva monitoring & $\begin{array}{l}\text { Proof-of-concept study, } \\
\text { lacks integration into } \\
\text { wearable device }\end{array}$ & [91] \\
\hline Glucose & $\begin{array}{l}\text { Bedside } \\
\text { monitoring }\end{array}$ & Optical (SPR) & $\begin{array}{l}\text { Metamaterial and } \\
\mathrm{SiO}_{2} \text {-based SPR }\end{array}$ & Urine monitoring & $\begin{array}{l}\text { High reliance on } \\
\text { reflective dip angles, } \\
\text { competing assays } \\
\text { already in market }\end{array}$ & [92] \\
\hline $\begin{array}{l}\text { Hemoglobin and } \\
\text { glucose }\end{array}$ & In-vitro model & Optical (SPR) & $\begin{array}{c}\text { Prism }\left(\mathrm{BK}_{7}\right) \text {, gold, } \\
\mathrm{PtSe}_{2} \text {, and graphene }\end{array}$ & $\begin{array}{l}\text { Blood and urine } \\
\text { monitoring }\end{array}$ & $\begin{array}{l}\text { Invasiveness, } \\
\text { proof-of-concept } \\
\text { studies, lacks } \\
\text { integration into } \\
\text { wearable devices }\end{array}$ & [93] \\
\hline $\begin{array}{l}\text { Reflectance due to } \\
\text { pulse deformation }\end{array}$ & Wristband & Optical fiber & $\begin{array}{l}\text { Polydimethylsiloxane } \\
\text { (PDMS) }+\mathrm{Ag} \\
\text { composite } \\
\text { diaphragm }\end{array}$ & $\begin{array}{l}\text { Blood pressure } \\
\text { monitoring }\end{array}$ & $\begin{array}{l}\text { Optimization and } \\
\text { display integration into } \\
\text { wrist devices could be } \\
\text { expensive }\end{array}$ & [99] \\
\hline $\begin{array}{l}\text { Perturbation and } \\
\text { fiber displacement } \\
\text { by external forces }\end{array}$ & Textile-based & Optical fiber & $\begin{array}{l}\text { Magnesium- and } \\
\text { erbium-coated } \\
\text { nanoparticle optical } \\
\text { fiber (NPF) }\end{array}$ & $\begin{array}{l}\text { Motion and } \\
\text { movement } \\
\text { detection }\end{array}$ & $\begin{array}{l}\text { Textile shelf-life, } \\
\text { cleaning challenges }\end{array}$ & [104] \\
\hline $\begin{array}{l}\text { Temperature, } \\
\text { transverse force, } \\
\text { and angular } \\
\text { displacements }\end{array}$ & Textile-based & Optical fiber & $\begin{array}{l}\text { Polymer optic fiber } \\
\text { (POF) using light } \\
\text { polymerization } \\
\text { spinning (LPS) }\end{array}$ & $\begin{array}{l}\text { Motion and } \\
\text { movement } \\
\text { detection }\end{array}$ & $\begin{array}{l}\text { Textile shelf-life, fiber } \\
\text { disturbance during } \\
\text { usage, and cleaning } \\
\text { challenges }\end{array}$ & [102] \\
\hline $\begin{array}{l}\text { Hydrogen } \\
\text { peroxide and ROS } \\
\text { (reactive oxygen } \\
\text { species) }\end{array}$ & Textile-based & Optical fiber & $\begin{array}{l}\text { Optical core-shell } \\
\text { microfibrous textile } \\
\text { with SWCNTs }\end{array}$ & Wound monitoring & $\begin{array}{l}\text { Novel design but } \\
\text { patient comfort and } \\
\text { wearable design } \\
\text { considerations for site } \\
\text { of wound }\end{array}$ & [103] \\
\hline
\end{tabular}


Table 1. Cont.

\begin{tabular}{|c|c|c|c|c|c|c|}
\hline $\begin{array}{l}\text { Analyte, } \\
\text { Parameter }\end{array}$ & $\begin{array}{l}\text { Wearable } \\
\text { Platform }\end{array}$ & $\begin{array}{c}\text { Mode of } \\
\text { Transduction }\end{array}$ & Materials & Application & Challenges & Ref. \\
\hline $\begin{array}{l}\text { PPG-based tissue } \\
\text { oxygen/blood } \\
\text { saturation }\end{array}$ & Earbud & Optical fiber free & $\begin{array}{l}\text { CMOS image sessor } \\
\text { (CIS) with Bluetooth, } \\
\text { power unit, and } \\
\text { microcontroller }\end{array}$ & $\begin{array}{l}\text { Heart rate } \\
\text { monitoring }\end{array}$ & $\begin{array}{l}\text { Commercialization and } \\
\text { cost factors due to } \\
\text { competing tech, and } \\
\text { communication/power } \\
\text { drawbacks needs to be } \\
\text { addressed }\end{array}$ & [113] \\
\hline $\begin{array}{l}\text { PPG-based tissue } \\
\text { oxygen/blood } \\
\text { saturation }\end{array}$ & Ring & Optical fiber free & $\begin{array}{l}\text { CMOS image sensor } \\
\text { with Bluetooth, } \\
\text { power unit, and } \\
\text { microcontroller }\end{array}$ & $\begin{array}{l}\text { Heart rate } \\
\text { monitoring }\end{array}$ & $\begin{array}{l}\text { Communication/power } \\
\text { drawbacks and cost } \\
\text { needs to be addressed } \\
\text { for large-scale } \\
\text { commercial applications }\end{array}$ & [108] \\
\hline
\end{tabular}

\section{Material Considerations in Wearable Biosensors}

\subsection{Carbon-Based Sensors}

\subsubsection{Graphene-Based Sensor Materials}

Graphene has a honeycomb-like hexagonal carbon lattice arranged in sp2 hybridization, with sheets stacked in layers with van der Waals forces. Its peculiar structure gives it unique properties, like high electron mobility, good thermal conductivity, remarkable mechanical strength, and broad band light absorption. Graphene arranged in cylinders forms carbon nanotubes, and a in hollow sphere forms fullerenes. Limitations remain with its use given its low throughput yield and high cost, making its use restricted to research labs and academia [114]. Thus, there is a constant effort to build its hybrids, the most common being graphene oxide (GO) and reduced graphene oxide (RGO). Various sensing technologies developed using such hybrids include electrical sensors (resistive and FET (field-effect transistor)-based), electrochemical sensors, and optical sensors, including fluorescence-based sensors. A field-effect transistor (FET), as the name implies, functions by changes in the electrical current in the semiconductor channel in the presence of an ion on the sensor surface. The use of graphene in biosensors showed improved detection and sensitivity when compared to traditional bioassays [115]. Fu et al. (2017) achieved a detection level in picomolar concentration by the non-covalent functionalization of GO using HIV-related DNA hybridization [116]. Fluorescence-based sensors have also been explored for the detection of biomolecules. GO offers the dual advantage of being a fluorescent chromophore and a fluorescence quencher. A novel strategy was developed by Dong et al. (2010), where they utilized the interaction of GO with quantum dots (QD). Natively fluorescent QDs, functionalized with complementary DNA fragments, were quenched of their fluorescence upon their interaction with the GO surface. In the presence of the target DNA, this interaction was lost due to an increase in distance, thus sustaining the fluorescence [117].

Surface-enhanced Raman scattering sensing (SERS) is another optical sensing mechanism widely used in biosensors (Figure 9). The addition of graphene to SERS substrates provides better stability, sensitivity, and biocompatibility. Duan et al. (2015) developed a multilayered PEGylated (PEG: polyethylene glycol) nanosheet for multiplexed DNA detection, in particular for bacterial pathogens. Even with the wide range of research available on graphene-based sensors [118], there is still a long way ahead before they can be popularly integrated into day-to-day life, given the complexity, cost, and optimization required. Nonetheless, graphene-based materials offer high-quality sensing, which is worth the investment in terms of time, money, and resources. 


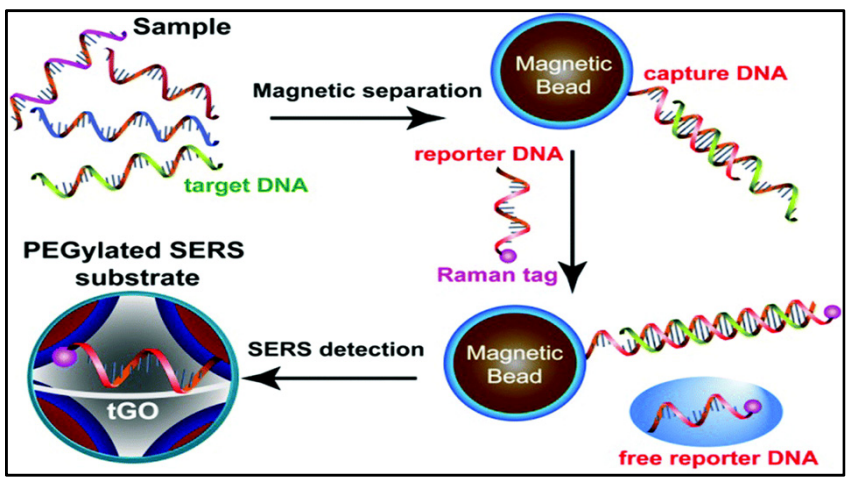

Figure 9. Mechanistic illustration of graphene-based substrates for SERS optical sensing. Image reprinted with permission from [119], under https://creativecommons.org/licenses/by-nc/3.0/, accessed on 26 November 2021.

\subsubsection{Carbon Dots}

Carbon dots are an invention discovered serendipitously [120]. They are a zerodimensional carbon-based material with a dimension of less than $10 \mathrm{~nm}$. They have a tunable fluorescence emission, which makes it possible to adapt them to function in visible light and the non-infrared (NIR) region. This property is indispensable in biological environments, as this range is not damaging, as opposed to the UV spectrum. Their surface has oxygen-containing functional groups that allow for easy modification and molecule integration [121]. Their inert nature and stability in biological systems provide excellent biocompatibility and low toxicity. Generally, CDs can be classified into four categories: graphene quantum dots (GQDs), carbon quantum dots (CQDs), carbon nanodots (CNDs), and carbonized polymer dots (CPDs). CPDs are the newest inclusion, owing to the advent of organic monomer-based production of CDs using citric acid, urea, etc. CDs can be simultaneously used for imaging as well as drug-releasing pharmacologic functions [122]. The electrochemical-sensing mechanism utilizes the high electron transport capability of CDs for the sensitive detection of metabolites and ions [123]. Jiang et al. (2015) developed a dopamine biosensor, where dopamine reacted with the multiple carboxyl groups on the sensor surface, leading to a change in the electrical signal detected even at nanomolar concentrations [124]. Buk et al. (2019) immobilized glucose oxidase on a CQD-gold nanoparticle hybrid for highly sensitive glucose detection [125]. The optical sensing mechanism is also highly utilized in CDs, where they can be merged with nanoparticles like gold for increased signal production. CDs derived from phenylboronic acid utilized the interaction of glucose with surface boric acid to quench the fluorescence. It provided a sensitivity 250 times higher than previous boric acid nano-sensing detection systems [126]. Highly specific uric acid detection was utilized by Wang et al. (2016) with sulfur-nitrogen co-doped carbon dots [127].

In addition to direct detection, enzymatic activity can also be detected using substrate reactions rather than the target molecule itself. Such biosensors have been developed using both electrochemical [128] as well as optical-sensing mechanisms [129,130]. Other methodologies like antigen-antibody interaction [131] and nucleic acid [132] integration have also been explored using these highly versatile nano dots. HIV detection was achieved at a femtomolar level using this technological advancement [132].

\subsubsection{Carbon Nanotubes}

Carbon nanotubes (CNTs) are an allotrope of carbon, which can be summarized as a cylindrical graphene. They have high mechanical strength, a large surface area, and excellent electrical and thermal conductivity [133]. However, there are strong $\pi-\pi$ surface interactions, which makes them highly hydrophobic, limiting their functionality. Thus, activation is carried through various ways to increase their electrochemical properties, which in turn increase the sensitivity and often the specificity of the sensor [134]. They have 
been functionalized with various small molecules and enzymes for target-specific analyte detection, like nicotinamide adenine dinucleotide (NAD) [135], glucose oxidase [136], cholesterol oxidase [137], urease [138], and lactic-acid oxidase [139] (Figures 10 and 11). CNTs are a vast field of research that cannot be covered completely in our review. More detailed discussions on CNTs, both single and multiwalled (MWCNTs), can be found in these papers $[140,141]$.

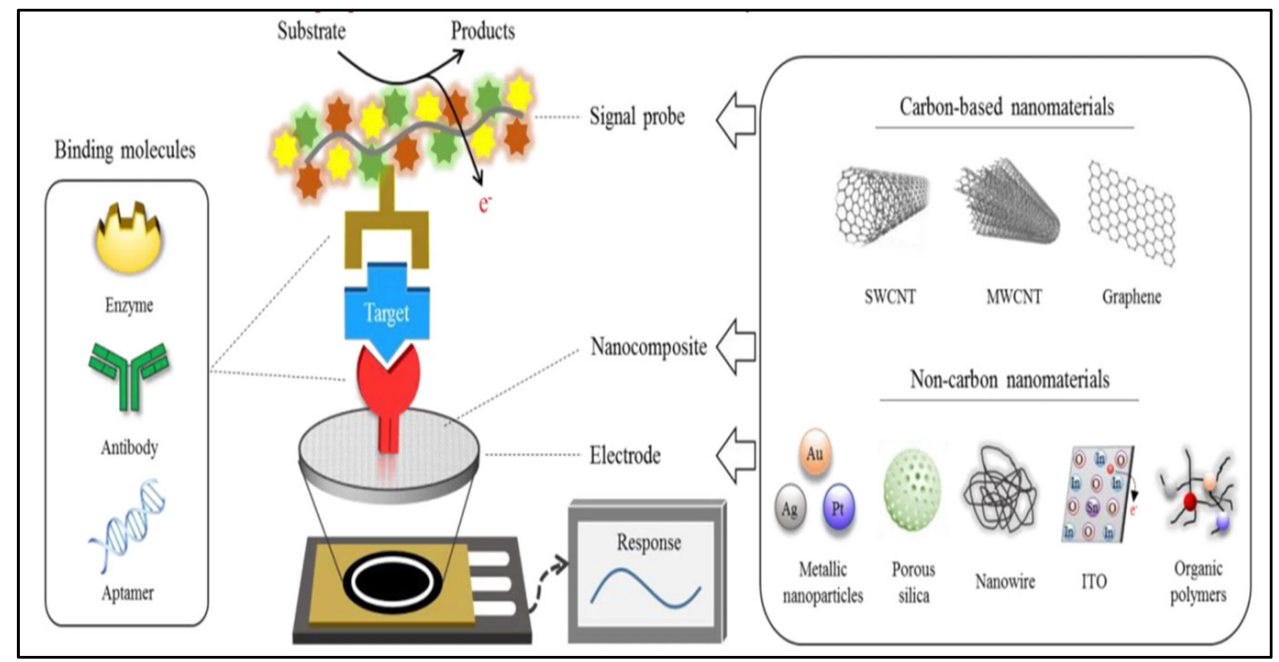

Figure 10. Mechanistic illustration of the principle of electrochemical biosensors based on carbon and non-carbon nanomaterials. Image reprinted with permission from [35], http:/ / creativecommons. org/licenses/by/4.0/, accessed on 26 November 2021.

\subsection{Non-Carbon-Based Sensor Materials Metal-Based Ceramics}

(a) Silicon-based sensors: Silicon-based sensors include electrochemically active Si nanowires, optical porous silicone [142], photonic crystals, and luminescent quantum dots and wires. Their role in microfluidics for electrical, optical, and piezoelectric sensors has been studied and applied [143]. Electrical sensors are fabricated more commonly using Si nanowires and porous silicone. Porous silicone of 50-200 $\mu \mathrm{m}$ is used. Nanomolar levels of lipopolysaccharides (LPS) for bacterial presence along with high specificity was achieved by using an LPS-specific polymyxin B receptor probe. Song et al. (2007) developed a point-of-care cholesterol, bilirubin, and glutamate biosensor for liver diseases utilizing the increase in surface area of the porous silicone [144]. Meanwhile, the silicon nanowires provide a passive microfluidic-like structure due to capillary action, bringing down the detection limits to picomolar and femtomolar levels [145]. Optical sensing is also performed by the nanoporous silicone particles [146]. Photonic crystals (PhC) and silicon nanocrystals primarily function through optical pathways. FRET-based detection of Staphylococcus aureus was performed with a detection limit of $8 \times 10^{-14} \mathrm{M}$ using porous photonic crystals [147]. Silicon-based materials provide one of the most sensitive platforms for biosensing, but their manufacturing process and integration with other metal and non-metallic components remains highly demanding, thus limiting their largescale production and use.

(b) Zinc oxide $(\mathrm{ZnO})$ : Given the wide bandgap (3.37 eV) and high exciton-binding energy $(60 \mathrm{meV})$ at room temperature, $\mathrm{ZnO}$ is one of the most ideal semiconductors for biosensors. Its high performance is owed to its excellent optical, piezoelectric, and electrochemical properties, along with the large surface area [148]. It is used in various shapes and sizes, ranging from zero dimensional QDs, one-dimensional wires and needles, and two-dimensional films, to three-dimensional porous materials and nanoclusters. There is a proof of concept for its use in neural [149], amino acid [150], and glucose-level [151] detection, as well as DNA hybridization [152]. 
(c) Aluminum oxide $\left(\mathrm{Al}_{2} \mathrm{O}_{3}\right)$ : Aluminum oxide-based materials are used in bioconductors due to their high dielectric constant, hardness, thermal stability, uniform pore size, and high pore density. Moreover, they are relatively less costly and the synthesis procedures are simple [153]. A CNT $/ \mathrm{Al}_{2} \mathrm{O}_{3} /$ chitosan hybrid was used to measure serotonin levels, which is an indicator of neural activity [154]. It has been used with GO [155], gold [156], polylysine [157], and titanium oxides [158] for various degradable as well as non-degradable biosensors.

\subsection{Organic Materials}

Natural biopolymer-based conductors mainly have two components: conductive fillers and an elastomeric polymer. Conductive fillers can be carbon based (graphene, CNT, CDs), metallic (metal oxides or noble metals), polymers and ionic liquids, or salts. The polymeric part can include synthetic polymers such as polydimethylsiloxane (PDMS), aka Ecoflex; polyurethane; polystyrene; or natural biopolymers—silk, gelatin, alginate, cellulose, or chitosan [159]. They have an advantage over other biosensing materials by being highly stretchable, mimicking biological tissues; are biocompatible; and are sustainable due to their biodegradability and natural abundance. The addition of conductive fillers imparts the required conductivity for imbibing electrical or optical properties. They provide wide applications from on-skin, textile wearable to implantable. They can be either bioinert or biodegradable, depending on the required conditions.

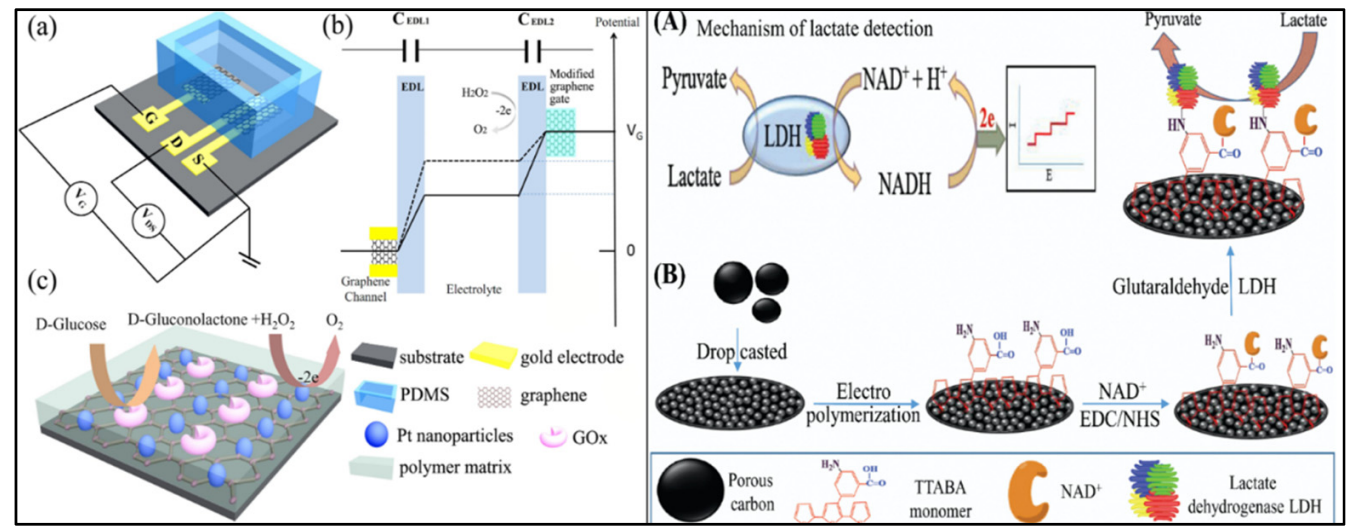

Figure 11. Mechanistic illustration of glucose (left) and lactate (right) detection. On the left, (a) schematic representation of a glucose sensor based on solution-gated graphene transistors (SGGT), (b) a drop in potential across the two EDLs (electric di-layers), (c) the GO-x catalyzed oxidation of glucose and oxidation of $\mathrm{H}_{2} \mathrm{O}_{2}$ on the electrode of the SGGT. Image reprinted with permission from [160], licensed under http:/ / creativecommons.org/licenses/by-nc-nd/4.0/, accessed on 26 November 2021. On the right, (A) schematic illustration of the mechanism of lactate detection and (B) the fabrication of a lactate biosensor. Abbr. EDC/NHS (ethyl(dimethylaminopropyl) carbodiimide $/ N$ Hydroxysuccinimide), TTABA monomer ((poly 3-(( $2,2^{\prime}: 5^{\prime}, 2^{\prime \prime}$-terthiophen)-3'-yl)-5-aminobenzoic acid). Image reprinted with permission from [161] Copyrights (2020), Elsevier.

\subsubsection{Natural Polymers}

(a) Polysaccharides: Cellulose is one of the most abundant polysaccharides present in nature, being present in early organisms like bacteria to more complex plants. It consists of branched polyglucan chains with multiple sites for hydrogen bonding, which imparts low solubility but high strength and flexibility at the same time. Cellulose-based biosensors have been widely studied for the detection of small molecules, nucleotides and DNA, proteins, glycoproteins, cancer and bacterial cells, and viruses. Chitin is the most abundant amino polysaccharide, where the amino groups make it possible to modify its properties in multiple ways. Chitosan is a deacetylated chitin derivative, with a more tunable structure, due to which it has acquired popularity over chitin in the biomedical research field. It has 
been used in conjugation with CNTs [162], graphene [163], and metals [164,165] for a wide range of molecular and cellular detection (Figure 11).

Another polysaccharide, alginate, is derived from brown seaweed with abundant use in biomedical applications. It can be modified into various forms, like fibers [166], sheets [167], and gels [168], as well as non-woven fabrics [169]. Ultra-high stretchability along with excellent fracture toughness is achieved by crosslinking with polymers like polyacrylamide (PAAm) and polyethylene glycol diacrylate (PEGDA) [170]. The dual detection of electrophysical and mechanical changes was achieved with the alginate PAAm hydrogel and polydimethylsiloxane (PDMS) film, paving the way for their use in biological situations involving coupled electromechanical reactions [171,172].

(b) Proteins: Protein-based natural polymers include silk and gelatin. Recently, silk was given FDA IDE approval owing to its biocompatibility [173]. It consists of two types of chains; one is fibrous, called silk fibroin (SF), and the other is stickier, called sericin. SF is usually utilized in biomedical applications, where it can be used as a substrate as well as a matrix for conductive filler materials. SF has hydrophilic amide groups, hydrophobic areas, and multiple functional groups, giving it the versatility to be conjugated with various filler materials. It has been integrated with gold nanoparticles [12], graphene(GO) [174], CNTs [175], and polystyrene sulphonate (PEDOT: PSS) [176] for various applications-for example, skin patches for electromyography (EMG) [177], cardiac mesh electrodes [178], and textile electrodes for physiological monitoring [176]. Biocompatible and conductive hydrogels crosslinked with gelatin have led to the development of biomimetic sensors that exhibit the advantages of natural polymers with enhanced physical and electrical properties. Gelatin meth acryloyl (GelMA) with DNA was used to conjugate with CNTs for increased strain tolerance [179]. Similarly, cross linking with polyvinyl alcohol (PVA) provided stretchability compared to natural skin, making it the ideal candidate for on-skin biosensing patches [180]. Though natural polymers have high biocompatibility, their use is not without drawbacks. Their complex structure and lot-to-lot variability limits their widescale manufacturing and use.

\subsubsection{Synthetic Polymers}

Polymers can comprise a range of different functional moieties, like esters, urethane, phosphate, carbonate, amide, anhydride, and imide, such as poly( $\alpha$-esters), polycaprolactone (PCL), polydioxanone, polyhydroxybutyrate, polyhydroxyvalerate, polyurethanes, and polyphosphazenes. Amongst polymers, esters like PCL and poly-glycolide (PGA) have been approved by the FDA due to their high biocompatibility [181]. Additionally, there is a class called intrinsically conducting polymers (ICP) that have an inherent electrical conductivity that can further be enhanced with organic and inorganic element addition. They include polypyrrol (PPy), polyaniline (PAni), and poly(3,4-ethylenedioxythiophene) (PEDOT) $[181,182]$. As mentioned at various places above, synthetic polymers have been used in conjugation with other conducting and optically active substrates to build a multitude of biosensing units [183]. Synthetic polymers can be more expensive than naturally available biodegradable polymers, but their advantage is a controlled synthesizing process. It ensures reproducible composition, electrochemical properties, and controlled degradation rates [183].

\section{Conclusions and Future Perspectives}

As presented in this review, the development of nanomaterials has resulted in novel ways to integrate biosensors into wearable devices while maintaining high selectivity of analytes and accurate biosensing. However, there are still challenges that remain in the development and eventual commercialization of such devices. The most significant hurdle that remains in fabricating these devices is employing materials and methods that are environmentally friendly, biocompatible, low-cost, and scalable. Although there has been significant development of biocompatible platforms and materials in sensors, there are still certain elements that limit the biocompatibility. Furthermore, some of these materials 
are prone to degradation over time and thus limit the life of the biosensor. With wearable biosensors, the nature of the functioning on the human body brings with it complicating factors such as temperature, moisture, and constant deformity. Each factor needs to be considered in the design to ensure proper functionality and accurate readouts. Apart from maintaining proper functionality, future wearable biosensors should incorporate additional features to create a user-friendly experience. In this review, we have provided a brief overview of the materials used in biosensing applications. Each material described has undergone extensive research with a plethora of literature, which is beyond the scope of our manuscript. Nonetheless, most important materials and their properties have been highlighted, which will serve as an essential tool for early researchers as well as other scientists. We can see how these materials can undergo various modifications and combinations to achieve the desired material properties. The goal is ultimately to build the most biomimetic tool possible that is biocompatible, highly sensitive, flexible, preferably compact, and adaptive to the dynamic biological and physical environment. Although there has been a great progress with respect to the materials, the cost and restricted access to technologies involved often limit their presence in research labs.

In the future, focus on better comfort, wireless communication, and sustainable power sources are a few of the challenges that need to be addressed to successfully integrate wearable devices. For example, although some wearables are battery powered, some take advantage of the energy generated by the human body that wears them to function. Further investigation on the use of solar cells and kinetic energy for powering wearable devices should be addressed. Another platform of recent interest is the rise of hydrogelbased biosensors that are deformable, biocompatible, and have self-healing properties, which addresses many of the challenges faced with stiffer 2D nanomaterials. Skin-printed electronic biosensors are an alternate, upcoming platform of biosensors that provides a viable solution to many of the issues discussed in our review, such as bulky sensor design, poor skin-surface interaction, the inability to accurately collect readouts, etc. Recently, a new wave of interest on wearable prosthesis has been largely welcomed by the medical community, alongside the tech industry. Intelligent robotic devices such as prosthetic limbs that can be gesture controlled or even respond to cerebral signals are being designed and normalized. With the rapid assimilation of AI into wearable devices, there should a focus on data collection and privacy policies that should be dealt with carefully to allow for safe and practical utilization. However, all these factors considered, more cost-efficient, easy-to-use, and accessible technologies for material and thereby device manufacture and development needs to be set in place to ensure their widescale progress and use in day-to-day biomedical applications. With further investigation into these technologies and their incorporation, the future of wearable biosensors is quite promising in biomedical applications, mainly in remote healthcare monitoring.

Author Contributions: Conceptualization, S.P. and S.D.T.; investigation, S.P.; writing-original draft preparation, S.P., A.U. and D.S.; writing-review and editing, S.P., B.H.N. and S.D.T.; supervision, S.D.T.; project administration, S.P. and S.D.T. All authors have read and agreed to the published version of the manuscript.

Funding: This research received no external funding.

Acknowledgments: The authors thank B.H. Nguyen for providing valuable insights on the writing and proofreading of this manuscript. The authors would also like to thank Alexandra Kohn, Digital Collections and Copyrights Librarian at McGill University, for providing assistance with copyrights and permissions for the images used in this manuscript.

Conflicts of Interest: The authors declare no conflict of interest.

\section{References}

1. Nikhil, B.; Pawan, J.; Nello, F.; Pedro, E. Introduction to biosensors. Essays Biochem. 2016, 60, 1-8.

2. Heineman, W.R.; Jensen, W.B. Leland c. clark jr. (1918-2005). Biosens. Bioelectron. 2006, 8, 1403-1404. [CrossRef]

3. Vestergaard, M. Nanobiosensors and Nanobioanalyses; Springer: Tokyo, Japan, 2015. 
4. Yoo, E.-H.; Lee, S.-Y. Glucose biosensors: An overview of use in clinical practice. Sensors 2010, 10, 4558-4576. [CrossRef]

5. Liedberg, B.; Nylander, C.; Lunström, I. Surface plasmon resonance for gas detection and biosensing. Sens. Actuators 1983, 4, 299-304. [CrossRef]

6. Narita, F.; Wang, Z.; Kurita, H.; Li, Z.; Shi, Y.; Jia, Y.; Soutis, C. A review of piezoelectric and magnetostrictive biosensor materials for detection of COVID-19 and other viruses. Adv. Mater. 2021, 33, 2005448. [CrossRef]

7. CBINSIGHTS. 24 Industries \& Technologies That Will Shape the Post-Virus World. Available online: https://www.cbinsights. $\mathrm{com} /$ research/report/industries-tech-shaping-world-post-covid/ (accessed on 27 January 2021).

8. Lee, E.K.; Yoo, H.; Lee, C.H. Advanced Materials and Assembly Strategies for Wearable Biosensors: A Review. In BiosensorsCurrent and Novel Strategies for Biosensing; Intech Open Limited: London, UK, 2020.

9. Mohankumar, P.; Ajayan, J.; Mohanraj, T.; Yasodharan, R. Recent developments in biosensors for healthcare and biomedical applications: A review. Measurement 2021, 167, 108293. [CrossRef]

10. Cesewski, E.; Johnson, B.N. Electrochemical biosensors for pathogen detection. Biosens. Bioelectron. 2020, 159, 112214. [CrossRef] [PubMed]

11. Liu, Q.; Zhao, C.; Chen, M.; Liu, Y.; Zhao, Z.; Wu, F.; Li, Z.; Weiss, P.S.; Andrews, A.M.; Zhou, C. Flexible multiplexed In $2 \mathrm{O}_{3}$ nanoribbon aptamer-field-effect transistors for biosensing. iScience 2020, 23, 101469. [CrossRef] [PubMed]

12. Choi, J.H.; Choi, M.; Kang, T.; Ho, T.S.; Choi, S.H.; Byun, K.M. Combination of Porous Silk Fibroin Substrate and Gold Nanocracks as a Novel SERS Platform for a High-Sensitivity Biosensor. Biosensors 2021, 11, 441. [CrossRef] [PubMed]

13. Luka, G.; Ahmadi, A.; Najjaran, H.; Alocilja, E.; DeRosa, M.; Wolthers, K.; Malki, A.; Aziz, H.; Althani, A.; Hoorfar, M. Microfluidics integrated biosensors: A leading technology towards lab-on-a-chip and sensing applications. Sensors 2015, 15, 30011-30031. [CrossRef] [PubMed]

14. Pei, Z.; Yu, Z.; Li, M.; Bai, L.; Wang, W.; Chen, H.; Yang, H.; Wei, D.; Yang, L. Self-healing and toughness cellulose nanocrystals nanocomposite hydrogels for strain-sensitive wearable flexible sensor. Int. J. Biol. Macromol. 2021, 179, 324-332. [CrossRef] [PubMed]

15. Ashley, B.K.; Brown, M.S.; Park, Y.; Kuan, S.; Koh, A. Skin-inspired, open mesh electrochemical sensors for lactate and oxygen monitoring. Biosens. Bioelectron. 2019, 132, 343-351. [CrossRef] [PubMed]

16. Saldanha, D.J.; Abdali, Z.; Modafferi, D.; Janfeshan, B.; Courchesne, N.-M.D. Fabrication of fluorescent pH-responsive proteintextile composites. Sci. Rep. 2020, 10, 1-12.

17. Zhao, C.; Li, X.; Wu, Q.; Liu, X. A thread-based wearable sweat nanobiosensor. Biosens. Bioelectron. 2021, 188, 113270. [CrossRef]

18. Vaquer, A.; Barón, E.; de la Rica, R. Wearable Analytical Platform with Enzyme-Modulated Dynamic Range for the Simultaneous Colorimetric Detection of Sweat Volume and Sweat Biomarkers. ACS Sens. 2020, 6, 130-136. [CrossRef]

19. Ding, J.; Qiao, Z.; Zhang, Y.; Wei, D.; Chen, S.; Tang, J.; Chen, L.; Wei, D.; Sun, J.; Fan, H. NIR-responsive multi-healing HMPAM/dextran/AgNWs hydrogel sensor with recoverable mechanics and conductivity for human-machine interaction. Carbohydr. Polym. 2020, 247, 116686. [CrossRef]

20. Vinoth, R.; Nakagawa, T.; Mathiyarasu, J.; Mohan, A.V. Fully Printed Wearable Microfluidic Devices for High-Throughput Sweat Sampling and Multiplexed Electrochemical Analysis. ACS Sens. 2021, 6, 1174-1186. [CrossRef]

21. Contacts vs. Glasses: The Pros and Cons. Available online: https:/ / ca.zennioptical.com/blog/contacts-vs-glasses / (accessed on 16 November 2021).

22. PARC Mouthguard Helps Track Athlete Fatigue through Saliva. Available online: https://www.sporttechie.com/xerox-parcnextflex-ucsd-saliva-mouthguard-athlete-fatigue/ (accessed on 16 November 2021).

23. Bioengineering, N. Wearable Patch Sends Simultaneous Signals of Health. Available online: https://www.nibib.nih.gov/newsevents/newsroom/wearable-patch-sends-simultaneous-signals-health (accessed on 16 November 2021).

24. Move over Fitbit: Sweat-Sensing Bracelet Could Be Next Wearable Tech. Available online: https://www.statnews.com/2016/01/ 27/sweat-wearable-tech/ (accessed on 16 November 2021).

25. Textile Pressure Sensors Can Be Washed. Available online: https://www.electronicsweekly.com/news/research-news/textilepressure-sensors-can-be-washed-2015-10/ (accessed on 16 November 2021).

26. Romeo, A.; Moya, A.; Leung, T.S.; Gabriel, G.; Villa, R.; Sanchez, S. Inkjet printed flexible non-enzymatic glucose sensor for tear fluid analysis. Appl. Mater. Today 2018, 10, 133-141. [CrossRef]

27. Biological Sensor Can Detect Glucose Levels in Saliva More Accurately and Cost-Efficiently than Blood Test. Available online: https:/ / phys.org/news/2017-05-biological-sensor-glucose-saliva-accurately.html (accessed on 16 November 2021).

28. Berkeley, U. Wearable Sensors Detect What's in Your Sweat. Available online: https://news.berkeley.edu/2019/08/16/wearablesensors-detect-whats-in-your-sweat/ (accessed on 16 November 2021).

29. Owyeung, R.E.; Terse-Thakoor, T.; Rezaei Nejad, H.; Panzer, M.J.; Sonkusale, S.R. Highly flexible transistor threads for all-thread based integrated circuits and multiplexed diagnostics. ACS Appl. Mater. Interfaces 2019, 11, 31096-31104. [CrossRef]

30. Wireless, Implantable Sensors the Size of a Grain of Sand Could Have Wide Use in Body Monitoring. Available online: https:/ / medicalxpress.com/news/2016-08-wireless-implantable-sensors-size-grain.html (accessed on 16 November 2021).

31. Grieshaber, D.; MacKenzie, R.; Vörös, J.; Reimhult, E. Electrochemical biosensors-sensor principles and architectures. Sensors 2008, 8, 1400-1458. [CrossRef]

32. Chaubey, A.; Malhotra, B. Mediated biosensors. Biosens. Bioelectron. 2002, 17, 441-456. [CrossRef] 
33. Guiseppi-Elie, A.; Lingerfelt, L. Impedimetric detection of DNA hybridization: Towards near-patient DNA diagnostics. In Immobilisation of DNA on Chips I; Springer: Berlin, Germany, 2005.

34. Thévenot, D.R.; Toth, K.; Durst, R.A.; Wilson, G.S. Electrochemical biosensors: Recommended definitions and classification. Biosens. Bioelectron. 2001, 16, 121-131. [CrossRef]

35. Cho, I.-H.; Kim, D.H.; Park, S. Electrochemical biosensors: Perspective on functional nanomaterials for on-site analysis. Biomater. Res. 2020, 24, 1-12. [CrossRef]

36. Lei, Y.; Zhao, W.; Zhang, Y.; Jiang, Q.; He, J.H.; Baeumner, A.J.; Wolfbeis, O.S.; Wang, Z.L.; Salama, K.N.; Alshareef, H.N. A MXene-based wearable biosensor system for high-performance in vitro perspiration analysis. Small 2019, 15, 1901190. [CrossRef]

37. Wang, Y.; Wang, X.; Lu, W.; Yuan, Q.; Zheng, Y.; Yao, B. A thin film polyethylene terephthalate (PET) electrochemical sensor for detection of glucose in sweat. Talanta 2019, 198, 86-92. [CrossRef] [PubMed]

38. Lee, H.; Hong, Y.J.; Baik, S.; Hyeon, T.; Kim, D.H. Enzyme-based glucose sensor: From invasive to wearable device. Adv. Healthc. Mater. 2018, 7, 1701150. [CrossRef]

39. Zhao, J.; Lin, Y.; Wu, J.; Nyein, H.Y.Y.; Bariya, M.; Tai, L.-C.; Chao, M.; Ji, W.; Zhang, G.; Fan, Z. A fully integrated and self-powered smartwatch for continuous sweat glucose monitoring. ACS Sens. 2019, 4, 1925-1933. [CrossRef]

40. Lin, K.-C.; Muthukumar, S.; Prasad, S. Flex-GO (Flexible graphene oxide) sensor for electrochemical monitoring lactate in low-volume passive perspired human sweat. Talanta 2020, 214, 120810. [CrossRef]

41. Goud, K.Y.; Moonla, C.; Mishra, R.K.; Yu, C.; Narayan, R.; Litvan, I.; Wang, J. Wearable electrochemical microneedle sensor for continuous monitoring of levodopa: Toward Parkinson management. ACS Sens. 2019, 4, 2196-2204. [CrossRef] [PubMed]

42. Wang, R.; Zhai, Q.; An, T.; Gong, S.; Cheng, W. Stretchable gold fiber-based wearable textile electrochemical biosensor for lactate monitoring in sweat. Talanta 2021, 222, 121484. [CrossRef] [PubMed]

43. Zhang, Q.; Jiang, D.; Xu, C.; Ge, Y.; Liu, X.; Wei, Q.; Huang, L.; Ren, X.; Wang, C.; Wang, Y. Wearable electrochemical biosensor based on molecularly imprinted Ag nanowires for noninvasive monitoring lactate in human sweat. Sens. Actuators B 2020, 320, 128325. [CrossRef]

44. Barfidokht, A.; Mishra, R.K.; Seenivasan, R.; Liu, S.; Hubble, L.; Wang, J.; Hall, D.A. Wearable electrochemical glove-based sensor for rapid and on-site detection of fentanyl. Sens. Actuators B 2019, 296, 126422. [CrossRef] [PubMed]

45. Zanfrognini, B.; Pigani, L.; Zanardi, C. Recent advances in the direct electrochemical detection of drugs of abuse. J. Solid State Electrochem. 2020, 24, 2603-2616. [CrossRef]

46. Rocha, R.G.; Stefano, J.S.; Arantes, I.V.; Ribeiro, M.M.; Santana, M.H.; Richter, E.M.; Munoz, R.A. Simple Strategy for Selective Determination of Levamisole in Seized Cocaine and Pharmaceutical Samples Using Disposable Screen-printed Electrodes. Electroanalysis 2019, 31, 153-159. [CrossRef]

47. Florea, A.; Cowen, T.; Piletsky, S.; De Wael, K. Electrochemical sensing of cocaine in real samples based on electrodeposited biomimetic affinity ligands. Analyst 2019, 144, 4639-4646. [CrossRef]

48. Tavakkoli, N.; Soltani, N.; Mohammadi, F. A nanoporous gold-based electrochemical aptasensor for sensitive detection of cocaine. RSC Adv. 2019, 9, 14296-14301. [CrossRef]

49. Renaud-Young, M.; Mayall, R.M.; Salehi, V.; Goledzinowski, M.; Comeau, F.J.; MacCallum, J.L.; Birss, V.I. Development of an ultra-sensitive electrochemical sensor for $\Delta$ 9-tetrahydrocannabinol (THC) and its metabolites using carbon paper electrodes. Electrochim. Acta 2019, 307, 351-359. [CrossRef]

50. Zhang, Q.; Berg, D.; Mugo, S.M. Molecularly imprinted carbon based electrodes for tetrahydrocannabinol sensing. Inorg. Chem. Commun. 2019, 107, 107459. [CrossRef]

51. Takeda, Y.; Kanai, M.; Hatano, A.; Yoshimi, Y.; Kida, M. A "single-use" ceramic-based electrochemical sensor chip using molecularly imprinted carbon paste electrode. Sensors 2020, 20, 5847.

52. Rawson, T.M.; Gowers, S.A.; Freeman, D.M.; Wilson, R.C.; Sharma, S.; Gilchrist, M.; MacGowan, A.; Lovering, A.; Bayliss, M.; Kyriakides, M. Microneedle biosensors for real-time, minimally invasive drug monitoring of phenoxymethylpenicillin: A first-in-human evaluation in healthy volunteers. Lancet Digit. Health 2019, 1, e335-e343. [CrossRef]

53. Ahmad-Tarar, A.; Mohammad, U.; Srivastava, S.K. Wearable skin sensors and their challenges: A review of transdermal, optical, and Mechanical Sensors. Biosensors 2020, 10, 56. [CrossRef] [PubMed]

54. Busch-Vishniac, I. Trends in electromechanical transduction. J. Acoust. Soc. Am. 1998, 103, 2860. [CrossRef]

55. Rim, Y.S.; Bae, S.H.; Chen, H.; De Marco, N.; Yang, Y. Recent progress in materials and devices toward printable and flexible sensors. Adv. Mater. 2016, 28, 4415-4440. [CrossRef]

56. Heikenfeld, J.; Jajack, A.; Rogers, J.; Gutruf, P.; Tian, L.; Pan, T.; Li, R.; Khine, M.; Kim, J.; Wang, J. Wearable sensors: Modalities, challenges, and prospects. Lab Chip 2018, 18, 217-248. [CrossRef] [PubMed]

57. Fan, F.-R.; Tian, Z.-Q.; Wang, Z.L. Flexible triboelectric generator. Nano Energy 2012, 1, 328-334. [CrossRef]

58. Chen, H.; Xu, Y.; Zhang, J.; Wu, W.; Song, G. Enhanced stretchable graphene-based triboelectric nanogenerator via control of surface nanostructure. Nano Energy 2019, 58, 304-311. [CrossRef]

59. Tang, N.; Zhou, C.; Qu, D.; Fang, Y.; Zheng, Y.; Hu, W.; Jin, K.; Wu, W.; Duan, X.; Haick, H. A Highly Aligned Nanowire-Based Strain Sensor for Ultrasensitive Monitoring of Subtle Human Motion. Small 2020, 16, 2001363. [CrossRef]

60. Wang, S.; Bai, Y.; Yang, X.; Liu, L.; Li, L.; Lu, Q.; Li, T.; Zhang, T. Highly stretchable potentiometric ion sensor based on surface strain redistributed fiber for sweat monitoring. Talanta 2020, 214, 120869. [CrossRef] 
61. Wang, C.; Li, X.; Gao, E.; Jian, M.; Xia, K.; Wang, Q.; Xu, Z.; Ren, T.; Zhang, Y. Carbonized silk fabric for ultrastretchable, highly sensitive, and wearable strain sensors. Adv. Mater. 2016, 28, 6640-6648. [CrossRef]

62. Yang, M.; Pan, J.; Xu, A.; Luo, L.; Cheng, D.; Cai, G.; Wang, J.; Tang, B.; Wang, X. Conductive cotton fabrics for motion sensing and heating applications. Polymers 2018, 10, 568. [CrossRef]

63. Bi, S.; Hou, L.; Zhao, H.; Zhu, L.; Lu, Y. Ultrasensitive and highly repeatable pen ink decorated cuprammonium rayon (cupra) fabrics for multifunctional sensors. J. Mater. Chem. A 2018, 6, 16556-16565. [CrossRef]

64. Ren, J.; Wang, C.; Zhang, X.; Carey, T.; Chen, K.; Yin, Y.; Torrisi, F. Environmentally-friendly conductive cotton fabric as flexible strain sensor based on hot press reduced graphene oxide. Carbon 2017, 111, 622-630. [CrossRef]

65. Liu, S.; Hu, M.; Yang, J. A facile way of fabricating a flexible and conductive cotton fabric. J. Mater. Chem. C 2016, 4, 1320-1325. [CrossRef]

66. Yang, S.; Li, C.; Chen, X.; Zhao, Y.; Zhang, H.; Wen, N.; Fan, Z.; Pan, L. Facile fabrication of high-performance pen ink-decorated textile strain sensors for human motion detection. ACS Appl. Mater. Interfaces 2020, 12, 19874-19881. [CrossRef] [PubMed]

67. Senthil, K.; Chen, P.-Y.; Ren, H. A review of printable flexible and stretchable tactile sensors. Research 2019, $2019,3018568$. [CrossRef] [PubMed]

68. Lee, K.; Ni, X.; Lee, J.Y.; Arafa, H.; David, J.P.; Xu, S.; Avila, R.; Irie, M.; Lee, J.H.; Easterlin, R.L. Mechano-acoustic sensing of physiological processes and body motions via a soft wireless device placed at the suprasternal notch. Nat. Biomed. Eng. 2020, 4 , 148-158. [CrossRef] [PubMed]

69. Mehta, D.D.; Zanartu, M.; Feng, S.W.; Cheyne II, H.A.; Hillman, R.E. Mobile voice health monitoring using a wearable accelerometer sensor and a smartphone platform. IEEE Trans. Biomed. Eng. 2012, 59, 3090-3096. [CrossRef]

70. Liu, Y.; Norton, J.J.; Qazi, R.; Zou, Z.; Ammann, K.R.; Liu, H.; Yan, L.; Tran, P.L.; Jang, K.-I.; Lee, J.W. Epidermal mechano-acoustic sensing electronics for cardiovascular diagnostics and human-machine interfaces. Sci. Adv. 2016, 2, e1601185. [CrossRef]

71. Jang, J.; Jun, Y.S.; Seo, H.; Kim, M.; Park, J.-U. Motion detection using tactile sensors based on pressure-sensitive transistor arrays. Sensors 2020, 20, 3624. [CrossRef]

72. Ozioko, O.; Karipoth, P.; Hersh, M.; Dahiya, R. Wearable assistive tactile communication interface based on integrated touch sensors and actuators. IEEE Trans. Neural Syst. Rehabil. Eng. 2020, 28, 1344-1352. [CrossRef]

73. Qi, K.; Wang, H.; You, X.; Tao, X.; Li, M.; Zhou, Y.; Zhang, Y.; He, J.; Shao, W.; Cui, S. Core-sheath nanofiber yarn for textile pressure sensor with high pressure sensitivity and spatial tactile acuity. J. Colloid Interface Sci. 2020, 561, 93-103. [CrossRef] [PubMed]

74. Yi, Q.; Najafikhoshnoo, S.; Das, P.; Noh, S.; Hoang, E.; Kim, T.; Esfandyarpour, R. All-3D-Printed, Flexible, and Hybrid Wearable Bioelectronic Tactile Sensors Using Biocompatible Nanocomposites for Health Monitoring. Adv. Mater. Technol. 2021, 2021, 2101034. [CrossRef]

75. Borisov, S.M.; Wolfbeis, O.S. Optical biosensors. Chem. Rev. 2008, 108, 423-461. [CrossRef]

76. Chen, C.; Wang, J. Optical biosensors: An exhaustive and comprehensive review. Analyst 2020, 145, 1605-1628. [CrossRef] [PubMed]

77. Zanchetta, G.; Lanfranco, R.; Giavazzi, F.; Bellini, T.; Buscaglia, M. Emerging applications of label-free optical biosensors. Nanophotonics 2017, 6, 627-645. [CrossRef]

78. Cooper, M.A. Optical biosensors in drug discovery. Nat. Rev. Drug Discov. 2002, 1, 515-528. [CrossRef] [PubMed]

79. Foubert, A.; Beloglazova, N.V.; Hedström, M.; De Saeger, S. Antibody immobilization strategy for the development of a capacitive immunosensor detecting zearalenone. Talanta 2019, 191, 202-208. [CrossRef] [PubMed]

80. Fernandes, E.; Cabral, P.D.; Campos, R.; Machado, G., Jr.; Cerqueira, M.F.; Sousa, C.; Freitas, P.P.; Borme, J.; Petrovykh, D.Y.; Alpuim, P. Functionalization of single-layer graphene for immunoassays. Appl. Surf. Sci. 2019, 480, 709-716. [CrossRef]

81. Estevez, M.C.; Alvarez, M.; Lechuga, L.M. Integrated optical devices for lab-on-a-chip biosensing applications. Laser Photonics Rev. 2012, 6, 463-487. [CrossRef]

82. Wong, L.S.; Khan, F.; Micklefield, J. Selective covalent protein immobilization: Strategies and applications. Chem. Rev. 2009, 109, 4025-4053. [CrossRef]

83. Mayer, K.M.; Lee, S.; Liao, H.; Rostro, B.C.; Fuentes, A.; Scully, P.T.; Nehl, C.L.; Hafner, J.H. A label-free immunoassay based upon localized surface plasmon resonance of gold nanorods. ACS Nano 2008, 2, 687-692. [CrossRef]

84. Dhanabalan, S.S.; Sriram, S.; Walia, S.; Avaninathan, S.R.; Carrasco, M.F.; Bhaskaran, M. Wearable Label-Free Optical Biodetectors: Progress and Perspectives. Adv. Photonics Res. 2021, 2, 2000076. [CrossRef]

85. Homola, J. Surface plasmon resonance sensors for detection of chemical and biological species. Chem. Rev. 2008, 108, 462-493. [CrossRef]

86. Dey, B.; Islam, M.S.; Park, J. Numerical design of high-performance $\mathrm{WS}_{2} /$ metal/ $\mathrm{WS}_{2} /$ graphene heterostructure based surface plasmon resonance refractive index sensor. Results Phys. 2021, 23, 104021. [CrossRef]

87. Rahman, M.M.; Rana, M.M.; Rahman, M.S.; Anower, M.; Mollah, M.A.; Paul, A.K. Sensitivity enhancement of SPR biosensors employing heterostructure of $\mathrm{PtSe}_{2}$ and 2D materials. Opt. Mater. 2020, 107, 110123. [CrossRef]

88. Jia, Y.; Li, Z.; Wang, H.; Saeed, M.; Cai, H. Sensitivity enhancement of a surface plasmon resonance sensor with platinum diselenide. Sensors 2020, 20, 131. [CrossRef] [PubMed]

89. Bijalwan, A.; Singh, B.K.; Rastogi, V. Surface plasmon resonance-based sensors using nano-ribbons of graphene and wse 2. Plasmonics 2020, 15, 1-9. [CrossRef] 
90. Zhang, Y.; Sun, J.; Liu, L.; Qiao, H. A review of biosensor technology and algorithms for glucose monitoring. J. Diabetes Compl. 2021, 35, 107929. [CrossRef] [PubMed]

91. Koushki, E.; Mohammadabadi, F.M.; Baedi, J.; Ghasedi, A. The effects of glucose and glucose oxidase on the Uv-vis spectrum of gold nanoparticles: A study on optical biosensor for saliva glucose monitoring. Photodiagn. Photodynam. Ther. 2020, $30,101771$. [CrossRef]

92. Yadav, A.; Sharan, P.; Kumar, A. Surface plasmonic resonance based five layered structure-biosensor for sugar level measurement in human. Results Opt. 2020, 1, 100002. [CrossRef]

93. Mostufa, S.; Paul, A.K.; Chakrabarti, K. Detection of hemoglobin in blood and urine glucose level samples using a graphene-coated SPR based biosensor. OSA Contin. 2021, 4, 2164-2176. [CrossRef]

94. Mitu, S.A.; Ahmed, K.; Al Zahrani, F.A.; Grover, A.; Rajan, M.S.M.; Moni, M.A. Development and analysis of surface plasmon resonance based refractive index sensor for pregnancy testing. Opt. Lasers Eng. 2021, 140, 106551. [CrossRef]

95. Alwis, L.; Sun, T.; Grattan, K. Developments in optical fibre sensors for industrial applications. Opt. Laser Technol. 2016, 78 , 62-66. [CrossRef]

96. Leal-Junior, A.G.; Diaz, C.A.; Avellar, L.M.; Pontes, M.J.; Marques, C.; Frizera, A. Polymer optical fiber sensors in healthcare applications: A comprehensive review. Sensors 2019, 19, 3156. [CrossRef]

97. Broadway, C.; Min, R.; Leal-Junior, A.G.; Marques, C.; Caucheteur, C. Toward commercial polymer fiber Bragg grating sensors: Review and applications. J. Lightwave Technol. 2019, 37, 2605-2615. [CrossRef]

98. Massaroni, C.; Zaltieri, M.; Presti, L.; Nicolò, A.; Tosi, D.; Schena, E. Fiber Bragg grating sensors for cardiorespiratory monitoring: A review. IEEE Sens. J. 2020, 13, 14069-14080. [CrossRef]

99. Li, L.; Li, Y.; Yang, L.; Fang, F.; Yan, Z.; Sun, Q. Continuous and Accurate Blood Pressure Monitoring Based on Wearable Optical Fiber Wristband. IEEE Sens. J. 2020, 21, 3049-3057. [CrossRef]

100. Shrestha, P.; Kim, J.-H.; Park, Y.; Kim, C.-G. Impact localization on composite structure using FBG sensors and novel impact localization technique based on error outliers. Compos. Struct. 2016, 142, 263-271. [CrossRef]

101. Ding, Z.; Wang, C.; Liu, K.; Jiang, J.; Yang, D.; Pan, G.; Pu, Z.; Liu, T. Distributed optical fiber sensors based on optical frequency domain reflectometry: A review. Sensors 2018, 18, 1072. [CrossRef]

102. Leal-Junior, A.; Avellar, L.; Frizera, A.; Marques, C. Smart textiles for multimodal wearable sensing using highly stretchable multiplexed optical fiber system. Sci. Rep. 2020, 10, 13867.

103. Safaee, M.M.; Gravely, M.; Roxbury, D. A Wearable Optical Microfibrous Biomaterial with Encapsulated Nanosensors Enables Wireless Monitoring of Oxidative Stress. Adv. Funct. Mater. 2021, 31, 2006254. [CrossRef]

104. Leal-Junior, A.G.; Ribeiro, D.; Avellar, L.M.; Silveira, M.; Díaz, C.A.R.; Frizera-Neto, A.; Blanc, W.; Rocon, E.; Marques, C. Wearable and fully-portable smart garment for mechanical perturbation detection with nanoparticles optical fibers. IEEE Sens. J. 2020, 21, 2995-3003. [CrossRef]

105. Zhu, H.T.; Zhan, L.W.; Dai, Q.; Xu, B.; Chen, Y.; Lu, Y.Q.; Xu, F. Self-Assembled Wavy Optical Microfiber for Stretchable Wearable Sensor. Adv. Opt. Mater. 2021, 9, 2002206. [CrossRef]

106. Pan, J.; Zhang, Z.; Jiang, C.; Zhang, L.; Tong, L. A multifunctional skin-like wearable optical sensor based on an optical micro-/nanofibre. Nanoscale 2020, 12, 17538-17544. [CrossRef]

107. Pang, Y.-N.; Liu, B.; Liu, J.; Wan, S.P.; Wu, T.; He, X.; Yuan, J.; Zhou, X.; Long, K.; Wu, Q. Wearable optical fiber sensor based on a bend singlemode-multimode-Singlemode fiber structure for respiration monitoring. IEEE Sens. J. 2020, 21, 4610-4617. [CrossRef]

108. Boukhayma, A.; Barison, A.; Haddad, S.; Caizzone, A. Ring-embedded micro-power mm-sized optical sensor for accurate heart beat monitoring. IEEE Access 2021, 9, 127217-127225. [CrossRef]

109. Cheng, R.; Shang, Y.; Hayes, D., Jr.; Saha, S.P.; Yu, G. Noninvasive optical evaluation of spontaneous low frequency oscillations in cerebral hemodynamics. Neuroimage 2012, 62, 1445-1454. [CrossRef]

110. Shang, Y.; Zhao, Y.; Cheng, R.; Dong, L.; Irwin, D.; Yu, G. Portable optical tissue flow oximeter based on diffuse correlation spectroscopy. Opt. Lett. 2009, 34, 3556-3558. [CrossRef]

111. Gurley, K.; Shang, Y.; Yu, G. Noninvasive optical quantification of absolute blood flow, blood oxygenation, and oxygen consumption rate in exercising skeletal muscle. J. Biomed. Opt. 2012, 17, 075010.

112. Mendelson, Y.; Ochs, B.D. Noninvasive pulse oximetry utilizing skin reflectance photoplethysmography. IEEE Trans. Biomed. Eng. 1988, 35, 798-805. [CrossRef]

113. Boukhayma, A.; Barison, A.; Haddad, S.; Caizzone, A. Earbud-embedded micro-power mm-sized optical sensor for accurate heart beat monitoring. IEEE Sens. J. 2021, 21, 19967-19977. [CrossRef]

114. Anichini, C.; Samori, P. Graphene-Based Hybrid Functional Materials. Small 2021, 17, e2100514. [CrossRef] [PubMed]

115. Xu, G.; Abbott, J.; Qin, L.; Yeung, K.Y.; Song, Y.; Yoon, H.; Kong, J.; Ham, D. Electrophoretic and field-effect graphene for all-electrical DNA array technology. Nat. Commun. 2014, 5, 4866. [CrossRef]

116. Fu, W.; Feng, L.; Panaitov, G.; Kireev, D.; Mayer, D.; Offenhausser, A.; Krause, H.J. Biosensing near the neutrality point of graphene. Sci. Adv. 2017, 3, e1701247. [CrossRef] [PubMed]

117. Dong, H.; Gao, W.; Yan, F.; Ji, H.; Ju, H. Fluorescence resonance energy transfer between quantum dots and graphene oxide for sensing biomolecules. Anal. Chem. 2010, 82, 5511-5517. [CrossRef] [PubMed] 
118. Duan, B.; Zhou, J.; Fang, Z.; Wang, C.; Wang, X.; Hemond, H.F.; Chan-Park, M.B.; Duan, H. Surface enhanced Raman scattering by graphene-nanosheet-gapped plasmonic nanoparticle arrays for multiplexed DNA detection. Nanoscale 2015, 7, 12606-12613. [CrossRef] [PubMed]

119. Gao, X.G.; Cheng, L.X.; Jiang, W.S.; Li, X.K.; Xing, F. Graphene and its Derivatives-Based Optical Sensors. Front. Chem. 2021, 9 , 615164. [CrossRef]

120. Xu, X.; Ray, R.; Gu, Y.; Ploehn, H.J.; Gearheart, L.; Raker, K.; Scrivens, W.A. Electrophoretic analysis and purification of fluorescent single-walled carbon nanotube fragments. J. Am. Chem. Soc. 2004, 126, 12736-12737. [CrossRef] [PubMed]

121. Wan, J.; Zhang, X.; Fu, K.; Zhang, X.; Shang, L.; Su, Z. Highly fluorescent carbon dots as novel theranostic agents for biomedical applications. Nanoscale 2021, 13, 17236-17253. [CrossRef]

122. Ji, C.; Zhou, Y.; Leblanc, R.M.; Peng, Z. Recent Developments of Carbon Dots in Biosensing: A Review. ACS Sens. 2020, 5, 2724-2741. [CrossRef]

123. Campuzano, S.; Yanez-Sedeno, P.; Pingarron, J.M. Carbon Dots and Graphene Quantum Dots in Electrochemical Biosensing Nanomaterials 2019, 9, 634. [CrossRef] [PubMed]

124. Jiang, Y.; Wang, B.; Meng, F.; Cheng, Y.; Zhu, C. Microwave-assisted preparation of N-doped carbon dots as a biosensor for electrochemical dopamine detection. J. Colloid Interface Sci. 2015, 452, 199-202. [CrossRef]

125. Buk, V.; Pemble, M.E. A highly sensitive glucose biosensor based on a micro disk array electrode design modified with carbon quantum dots and gold nanoparticles. Electrochim. Acta 2019, 298, 97-105. [CrossRef]

126. Shen, P.; Xia, Y. Synthesis-modification integration: One-step fabrication of boronic acid functionalized carbon dots for fluorescent blood sugar sensing. Anal. Chem. 2014, 86, 5323-5329. [CrossRef] [PubMed]

127. Wang, H.; Lu, Q.; Hou, Y.; Liu, Y.; Zhang, Y. High fluorescence S, N co-doped carbon dots as an ultra-sensitive fluorescent probe for the determination of uric acid. Talanta 2016, 155, 62-69. [CrossRef]

128. Sharma, S.K.; Micic, M.; Li, S.; Hoar, B.; Paudyal, S.; Zahran, E.M.; Leblanc, R.M. Conjugation of Carbon Dots with betaGalactosidase Enzyme: Surface Chemistry and Use in Biosensing. Molecules 2019, 24, 3275. [CrossRef]

129. Wang, Y.; Wang, Z.; Rui, Y.; Li, M. Horseradish peroxidase immobilization on carbon nanodots/CoFe layered double hydroxides: Direct electrochemistry and hydrogen peroxide sensing. Biosens. Bioelectron. 2015, 64, 57-62. [CrossRef]

130. Mohammadi, S.; Salimi, A.; Hamd-Ghadareh, S.; Fathi, F.; Soleimani, F. A FRET immunosensor for sensitive detection of CA 15-3 tumor marker in human serum sample and breast cancer cells using antibody functionalized luminescent carbon-dots and AuNPs-dendrimer aptamer as donor-acceptor pair. Anal. Biochem. 2018, 557, 18-26. [CrossRef]

131. Sarkar, T.; Bohidar, H.B.; Solanki, P.R. Carbon dots-modified chitosan based electrochemical biosensing platform for detection of vitamin D. Int. J. Biol. Macromol. 2018, 109, 687-697. [CrossRef]

132. Qaddare, S.H.; Salimi, A. Amplified fluorescent sensing of DNA using luminescent carbon dots and AuNPs/GO as a sensing platform: A novel coupling of FRET and DNA hybridization for homogeneous HIV-1 gene detection at femtomolar level. Biosens. Bioelectron. 2017, 89, 773-780. [CrossRef]

133. Rivas, G.A.; Rubianes, M.D.; Rodriguez, M.C.; Ferreyra, N.F.; Luque, G.L.; Pedano, M.L.; Miscoria, S.A.; Parrado, C. Carbon nanotubes for electrochemical biosensing. Talanta 2007, 74, 291-307. [CrossRef]

134. Sireesha, M.; Jagadeesh Babu, V.; Kranthi Kiran, A.S.; Ramakrishna, S. A review on carbon nanotubes in biosensor devices and their applications in medicine. Nanocomposites 2018, 4, 36-57. [CrossRef]

135. Meng, L.; Wu, P.; Chen, G.; Cai, C.; Sun, Y.; Yuan, Z. Low potential detection of glutamate based on the electrocatalytic oxidation of NADH at thionine/single-walled carbon nanotubes composite modified electrode. Biosens. Bioelectron. 2009, 24, 1751-1756. [CrossRef] [PubMed]

136. Boussema, F.; Gross, A.J.; Hmida, F.; Ayed, B.; Majdoub, H.; Cosnier, S.; Maaref, A.; Holzinger, M. Dawson-type polyoxometalate nanoclusters confined in a carbon nanotube matrix as efficient redox mediators for enzymatic glucose biofuel cell anodes and glucose biosensors. Biosens. Bioelectron. 2018, 109, 20-26. [CrossRef]

137. Zhu, L.; Xu, L.; Tan, L.; Tan, H.; Yang, S.; Yao, S. Direct electrochemistry of cholesterol oxidase immobilized on gold nanoparticlesdecorated multiwalled carbon nanotubes and cholesterol sensing. Talanta 2013, 106, 192-199. [CrossRef] [PubMed]

138. Hu, F.; Chen, S.; Wang, C.; Yuan, R.; Xiang, Y.; Wang, C. Multi-wall carbon nanotube-polyaniline biosensor based on lectincarbohydrate affinity for ultrasensitive detection of Con A. Biosens. Bioelectron. 2012, 34, 202-207. [CrossRef]

139. Dagar, K.; Pundir, C.S. An improved amperometric L-lactate biosensor based on covalent immobilization of microbial lactate oxidase onto carboxylated multiwalled carbon nanotubes/copper nanoparticles/polyaniline modified pencil graphite electrode. Enzym. Microb. Technol. 2017, 96, 177-186. [CrossRef] [PubMed]

140. Muhulet, A.; Miculescu, F.; Voicu, S.I.; Schütt, F.; Thakur, V.K.; Mishra, Y.K. Fundamentals and scopes of doped carbon nanotubes towards energy and biosensing applications. Mater. Today Energy 2018, 9, 154-186. [CrossRef]

141. Alim, S.; Vejayan, J.; Yusoff, M.M.; Kafi, A. Recent uses of carbon nanotubes \& gold nanoparticles in electrochemistry with application in biosensing: A review. Biosens. Bioelectron. 2018, 121, 125-136.

142. Yun, D.; Song, M.-J.; Hwang, S.; Hong, S.-I. Fabrication and electrochemical characterization of nanoporous silicon electrode for Amperometric urea biosensor. Jpn. J. Appl. Phys. 2012, 51, 06FG02. [CrossRef]

143. Leonardi, A.A.; Lo Faro, M.J.; Irrera, A. Biosensing platforms based on silicon nanostructures: A critical review. Anal. Chim. Acta 2021, 1160, 338393. [CrossRef] 
144. Song, M.J.; Yun, D.H.; Min, N.K.; Hong, S.I. Electrochemical biosensor array for liver diagnosis using silanization technique on nanoporous silicon electrode. J. Biosci. Bioeng. 2007, 103, 32-37. [CrossRef] [PubMed]

145. Hemmilä, S.; Gao, A.; Lu, N.; Li, T.; Wang, Y.; Kallio, P. Integration of microfluidic sample delivery system on silicon nanowirebased biosensor. Microsyst. Techol. 2015, 21, 571-580. [CrossRef]

146. Syshchyk, O.; Skryshevsky, V.A.; Soldatkin, O.O.; Soldatkin, A.P. Enzyme biosensor systems based on porous silicon photoluminescence for detection of glucose, urea and heavy metals. Biosens. Bioelectron. 2015, 66, 89-94. [CrossRef]

147. Krismastuti, F.S.; Cavallaro, A.; Prieto-Simon, B.; Voelcker, N.H. Toward Multiplexing Detection of Wound Healing Biomarkers on Porous Silicon Resonant Microcavities. Adv. Sci. 2016, 3, 1500383. [CrossRef] [PubMed]

148. Tereshchenko, A.; Bechelany, M.; Viter, R.; Khranovskyy, V.; Smyntyna, V.; Starodub, N.; Yakimova, R. Optical biosensors based on ZnO nanostructures: Advantages and perspectives. A review. Sens. Actuators B 2016, 229, 664-677. [CrossRef]

149. Zhao, L.; Li, H.; Meng, J.; Wang, A.C.; Tan, P.; Zou, Y.; Yuan, Z.; Lu, J.; Pan, C.; Fan, Y. Reversible conversion between schottky and ohmic contacts for highly sensitive, multifunctional biosensors. Adv. Funct. Mater. 2020, 30, 1907999. [CrossRef]

150. Alam, M.; Rahman, M.M.; Uddin, M.; Asiri, A.M.; Chani, M.T.S.; Islam, M. Development of l-glutamic acid biosensor with ternary $\mathrm{ZnO} / \mathrm{NiO} / \mathrm{Al}_{2} \mathrm{O}_{3}$ nanoparticles. J. Luminesc. 2020, 227, 117528. [CrossRef]

151. Zhao, M.; Shang, J.; Qu, H.; Gao, R.; Li, H.; Chen, S. Fabrication of the Ni/ZnO/BiOI foam for the improved electrochemical biosensing performance to glucose. Anal. Chim. Acta 2020, 1095, 93-98. [CrossRef]

152. Pal, S.; Prajapati, Y.K.; Saini, J. Influence of graphene's chemical potential on SPR biosensor using ZnO for DNA hybridization Opt. Rev. 2020, 27, 57-64. [CrossRef]

153. Subbaiah, G.B.; Ratnam, K.V.; Janardhan, S.; Shiprath, K.; Manjunatha, H.; Ramesha, M.; Prasad, N.V.K.; Ramesh, S.; Babu, T.A Metal and Metal Oxide Based Advanced Ceramics for Electrochemical Biosensors-A Short Review. Front. Mater. $2021,8,682025$. [CrossRef]

154. Wu, W.; Liu, C.; Huang, F.; Li, H.; Wang, Y.; Hong, D.; Wang, S.; Zeng, X. A simple and Novel Electroanalytical Method for Determination of Brain Serotonin Based on the MWNTs $/ \mathrm{Al}_{2} \mathrm{O}_{3} /$ chitosan SPE. Int. J. Electrochem. Sci. 2018, 13, 7129-7140. [CrossRef]

155. Mekawy, M.M.; Hassan, R.Y.; Ramnani, P.; Yu, X.; Mulchandani, A. Electrochemical detection of dihydronicotinamide adenine dinucleotide using $\mathrm{Al}_{2} \mathrm{O}_{3}$-GO nanocomposite modified electrode. Arab. J. Chem. 2018, 11, 942-949. [CrossRef]

156. Parvin, M.H.; Arjomandi, J.; Lee, J.Y. $\gamma-\mathrm{Al}_{2} \mathrm{O}_{3}$ nanoparticle catalyst mediated polyaniline gold electrode biosensor for vitamin $\mathrm{E}$ Catal. Commun. 2018, 110, 59-63. [CrossRef]

157. Wang, Y.; Xiong, Y.; Tian, H.; Wang, S.; Zhang, Q.; Zhang, M.; Ding, H.; Gu, Y.; Peng, A. Application of Sensitive Sensor Modified with MWNTs $/ \mathrm{Al}_{2} \mathrm{O}_{3} /$ poly-L-lysine Composite for $17 \beta$-estradiol Determination in Pregnant Woman Blood. Int. J. Electrochem. Sci. 2018, 13, 147-158. [CrossRef]

158. Rakib, R.H.; Hasnat, M.A.; Uddin, M.N.; Alam, M.; Asiri, A.M.; Rahman, M.M.; Siddiquey, I.A. Fabrication of a 3, 4Diaminotoluene Sensor Based on a $\mathrm{TiO}_{2}-\mathrm{Al}_{2} \mathrm{O}_{3}$ Nanocomposite Synthesized by a Fast and Facile Microwave Irradiation Method. Chem. Sel. 2019, 4, 12592-12600.

159. Spychalska, K.; Zając, D.; Baluta, S.; Halicka, K.; Cabaj, J. Functional polymers structures for (Bio) sensing application-A review. Polymers 2020, 12, 1154. [CrossRef]

160. Zhang, M.; Liao, C.; Mak, C.H.; You, P.; Mak, C.L.; Yan, F. Highly sensitive glucose sensors based on enzyme-modified whole-graphene solution-gated transistors. Sci. Rep. 2015, 5, 8311.

161. Hussain, K.K.; Gurudatt, N.; Akhtar, M.H.; Seo, K.-D.; Park, D.-S.; Shim, Y.-B. Nano-biosensor for the in vitro lactate detection using bi-functionalized conducting polymer/N, S-doped carbon; the effect of $\alpha \mathrm{CHC}$ inhibitor on lactate level in cancer cell lines. Biosens. Bioelectron. 2020, 155, 112094. [CrossRef] [PubMed]

162. Kuralay, F.; Vural, T.; Bayram, C.; Denkbas, E.B.; Abaci, S. Carbon nanotube-chitosan modified disposable pencil graphite electrode for vitamin B12 analysis. Colloids Surf. B Biointerfaces 2011, 87, 18-22. [CrossRef] [PubMed]

163. Xia, J.; Cao, X.; Wang, Z.; Yang, M.; Zhang, F.; Lu, B.; Li, F.; Xia, L.; Li, Y.; Xia, Y. Molecularly imprinted electrochemical biosensor based on chitosan/ionic liquid-graphene composites modified electrode for determination of bovine serum albumin. Sens. Actuators B 2016, 225, 305-311. [CrossRef]

164. Salvo-Comino, C.; Gonzalez-Gil, A.; Rodriguez-Valentin, J.; Garcia-Hernandez, C.; Martin-Pedrosa, F.; Garcia-Cabezon, C.; Rodriguez-Mendez, M.L. Biosensors Platform Based on Chitosan/AuNPs/Phthalocyanine Composite Films for the Electrochemical Detection of Catechol. The Role of the Surface structure. Sensors 2020, 20, 2152. [CrossRef]

165. Hroncekova, S.; Bertok, T.; Hires, M.; Jane, E.; Lorencova, L.; Vikartovska, A.; Tanvir, A.; Kasak, P.; Tkac, J. Ultrasensitive Ti ${ }_{3} C_{2}$ TX MXene/Chitosan Nanocomposite-Based Amperometric Biosensor for Detection of Potential Prostate Cancer Marker in Urine Samples. Processes 2020, 8, 580. [CrossRef] [PubMed]

166. Fu, X.; Liang, Y.; Wu, R.; Shen, J.; Chen, Z.; Chen, Y.; Wang, Y.; Xia, Y. Conductive core-sheath calcium alginate/graphene composite fibers with polymeric ionic liquids as an intermediate. Carbohydr. Polym. 2019, 206, 328-335. [CrossRef] [PubMed]

167. Kerdjoudj, H.; Boulmedais, F.; Berthelemy, N.; Mjahed, H.; Louis, H.; Schaaf, P.; Voegel, J.; Menu, P. Cellularized alginate sheets for blood vessel reconstruction. Soft Matter 2011, 7, 3621-3626. [CrossRef]

168. Gilshteyn, E.P.; Lin, S.; Kondrashov, V.A.; Kopylova, D.S.; Tsapenko, A.P.; Anisimov, A.S.; Hart, A.J.; Zhao, X.; Nasibulin, A.G A One-Step Method of Hydrogel Modification by Single-Walled Carbon Nanotubes for Highly Stretchable and Transparent Electronics. ACS Appl. Mater. Interfaces 2018, 10, 28069-28075. [CrossRef] [PubMed] 
169. Wang, F.; Jiang, J.; Sun, F.; Sun, L.; Wang, T.; Liu, Y.; Li, M. Flexible wearable graphene/alginate composite non-woven fabric temperature sensor with high sensitivity and anti-interference. Cellulose 2020, 27, 2369-2380. [CrossRef]

170. Yuk, H.; Zhang, T.; Parada, G.A.; Liu, X.; Zhao, X. Skin-inspired hydrogel-elastomer hybrids with robust interfaces and functional microstructures. Nat. Commun. 2016, 7, 12028. [CrossRef]

171. Cai, P.; Wan, C.; Pan, L.; Matsuhisa, N.; He, K.; Cui, Z.; Zhang, W.; Li, C.; Wang, J.; Yu, J.; et al. Locally coupled electromechanical interfaces based on cytoadhesion-inspired hybrids to identify muscular excitation-contraction signatures. Nat. Commun. 2020, 11, 2183. [CrossRef]

172. Pan, S.; Zhang, F.; Cai, P.; Wang, M.; He, K.; Luo, Y.; Li, Z.; Chen, G.; Ji, S.; Liu, Z. Mechanically Interlocked Hydrogel-Elastomer Hybrids for On-Skin Electronics. Adv. Funct. Mater. 2020, 30, 1909540. [CrossRef]

173. Yavuz, B.; Chambre, L.; Harrington, K.; Kluge, J.; Valenti, L.; Kaplan, D.L. Silk Fibroin Microneedle Patches for the Sustained Release of Levonorgestrel. ACS Appl. Bio Mater. 2020, 3, 5375-5382. [CrossRef]

174. Liang, B.; Fang, L.; Hu, Y.; Yang, G.; Zhu, Q.; Ye, X. Fabrication and application of flexible graphene silk composite film electrodes decorated with spiky Pt nanospheres. Nanoscale 2014, 6, 4264-4274. [CrossRef]

175. Ye, C.; Ren, J.; Wang, Y.; Zhang, W.; Qian, C.; Han, J.; Zhang, C.; Jin, K.; Buehler, M.J.; Kaplan, D.L. Design and fabrication of silk templated electronic yarns and applications in multifunctional textiles. Matter 2019, 1, 1411-1425. [CrossRef]

176. Ryan, J.D.; Mengistie, D.A.; Gabrielsson, R.; Lund, A.; Muller, C. Machine-Washable PEDOT:PSS Dyed Silk Yarns for Electronic Textiles. ACS Appl. Mater. Interfaces 2017, 9, 9045-9050. [CrossRef] [PubMed]

177. Baik, S.; Lee, H.J.; Kim, D.W.; Kim, J.W.; Lee, Y.; Pang, C. Bioinspired adhesive architectures: From skin patch to integrated bioelectronics. Adv. Mater. 2019, 31, 1803309. [CrossRef] [PubMed]

178. Song, Y.; Wang, H.; Yue, F.; Lv, Q.; Cai, B.; Dong, N.; Wang, Z.; Wang, L. Silk-Based Biomaterials for Cardiac Tissue Engineering. Adv. Healthc. Mater. 2020, 9, e2000735. [CrossRef]

179. Shin, S.R.; Farzad, R.; Tamayol, A.; Manoharan, V.; Mostafalu, P.; Zhang, Y.S.; Akbari, M.; Jung, S.M.; Kim, D.; Comotto, M.; et al. A Bioactive Carbon Nanotube-Based Ink for Printing 2D and 3D Flexible Electronics. Adv. Mater. 2016, 28, 3280-3289. [CrossRef] [PubMed]

180. Chen, H.; Ren, X.; Gao, G. Skin-Inspired Gels with Toughness, Antifreezing, Conductivity, and Remoldability. ACS Appl. Mater. Interfaces 2019, 11, 28336-28344. [CrossRef]

181. Regazzoli, D.; Leone, P.P.; Colombo, A.; Latib, A. New generation bioresorbable scaffold technologies: An update on novel devices and clinical results. J. Thorac. Dis. 2017, 9, S979-S985. [CrossRef]

182. Saberi, A.; Jabbari, F.; Zarrintaj, P.; Saeb, M.R.; Mozafari, M. Electrically conductive materials: Opportunities and challenges in tissue engineering. Biomolecules 2019, 9, 448. [CrossRef]

183. Lanzalaco, S.; Molina, B.G. Polymers and Plastics Modified Electrodes for Biosensors: A Review. Molecules 2020, $25,2446$. [CrossRef] [PubMed] 